\title{
TAMPA ELECTRIC NEURAL NETWORK SOOTBLOWING
}

Quarterly Report:

Apr 1, 2004 - Jun 30, 2004

Prepared By:

Mark A. Rhode, P.E. Sr. Consulting Engineer Advanced Technologies

Submission Date:

Aug 2004

DOE Award Number:

DE-FC26-02NT41425 


\section{DISCLAIMER}

"This report was prepared as an account of work sponsored by an agency of the United States Government. Neither the United States Government nor any agency thereof, nor any of their employees, makes any warranty, express or implied, or assumes any legal liability or responsibility for the accuracy, completeness, or usefulness of any information, apparatus, product, or process disclosed, or represents that its use would not infringe privately owned rights. Reference herein to any specific commercial product, process, or service by trade name, trademark, manufacturer, or otherwise does not necessarily constitute or imply its endorsement, recommendation, or favoring by the United States Government or any agency thereof. The views and opinions of authors expressed herein do not necessarily state or reflect those of the United States Government or any agency thereof.” 


\section{ABSTRACT:}

Boiler combustion dynamics change continuously due to several factors including coal quality, boiler loading, ambient conditions, changes in slag/soot deposits and the condition of plant equipment. NOx formation, Particulate Matter (PM) emissions, and boiler thermal performance are directly affected by the sootblowing practices on a unit.

As part of its Power Plant Improvement Initiative program, the US DOE is providing cofunding (DE-FC26-02NT41425) and NETL is the managing agency for this project at Tampa Electric's Big Bend Station. This program serves to co-fund projects that have the potential to increase thermal efficiency and reduce emissions from coal-fired utility boilers. A review of the Big Bend units helped identify intelligent sootblowing as a suitable application to achieve the desired objectives. The existing sootblower control philosophy uses sequential schemes, whose frequency is either dictated by the control room operator or is timed based.

The intent of this project is to implement a neural network based intelligent sootblowing system, in conjunction with state-of-the-art controls and instrumentation, to optimize the operation of a utility boiler and systematically control boiler fouling. Utilizing unique, on-line, adaptive technology, operation of the sootblowers can be dynamically controlled based on realtime events and conditions within the boiler. This could be an extremely cost-effective technology, which has the ability to be readily and easily adapted to virtually any pulverized coal fired boiler.

Through unique on-line adaptive technology, Neural Network-based systems optimize the boiler operation by accommodating equipment performance changes due to wear and maintenance activities, adjusting to fluctuations in fuel quality, and improving operating flexibility. The system dynamically adjusts combustion setpoints and bias settings in closedloop supervisory control to simultaneously reduce $\mathrm{NO}_{\mathrm{x}}$ emissions and improve heat rate around the clock. 


\section{TABLE OF CONTENTS}

Introduction

Executive Summary

Experimental

Results and Discussion

Conclusion

Appendices

Pegasus Monthly Reporting

Graphics

Figure 1: $\quad$ Proposed Communications Network

Figure 2\&3: $\quad$ Load vs. NOx vs. O2

Figure 4\&5: $\quad$ NOx vs. "D” Blowers vs. Heat Rate

Figure 6: $\quad$ Impact of Low Load vs. NOx with Sootblowers

Figure 7\&8: $\quad$ NOx vs. "E” Blowers vs. Heat Rate

Figure 9\&10: $\quad$ Reheater Performance vs. "D,E,F,G” Sootblowers

Figure 11,12 \& 13: Mill Operation vs. NOx

Figure 14: $\quad$ Mill Outlet Temperature vs. NOx

Figure 15 -19: $\quad$ NOx vs. Load vs. Sootblower Duty

Figure 20 -24: $\quad$ Boiler Efficiency vs. Load vs. Sootblower Duty

Figure 25: Water Cannon Test Results 


\section{INTRODUCTION:}

One of the effects of burning coal in utility boilers is the buildup of soot and slag on the heat transfer surfaces within the boiler. Soot and slag buildup causes a redistribution/reduction of the heat transferred across various sections of the furnace, resulting in a redistribution/reduction of heat absorption. This condition often leads to a heat rate penalty and increased NOx emissions. Adverse heat rate impacts arise from numerous factors inclusive of, but not necessarily limited to; incomplete combustion, unbalanced steam generation, excessive use of desuperheater sprays and high exit gas temperatures. Thermal NOx generation has been well documented as largely a function of temperatures within and around the combustion zone. As the boiler section of the furnace becomes excessively slagged, the heat transfer ability is impaired which results in higher temperatures within that region. This results in higher levels of NOx.

Fouling of the boiler leads to poor efficiencies due to the fact that heat which could normally be transferred to the working fluid remains in the flue gas stream and exits to the environment without beneficial use. This loss in efficiency translates to higher consumption of fuel for equivalent levels of electric generation, hence more gaseous emissions are also produced. Another less obvious problem exists with fouling of various sections of the boiler relating to the intensity of peak temperatures within and around the combustion zone. Total NOx generation is primarily a function of both fuel and thermal NOx production. Fuel NOx, which generally comprises $20 \%-40 \%$ of the total NOx generated, is predominately influenced by the levels of oxygen. Thermal NOx, which comprises approximately $20 \%-50 \%$ of the total NOx, is a function of temperature. As the fouling of the boiler increases and the rate of heat transfer decreases, peak temperature increases and so does the thermal NOx production.

Due to the composition of coal, particulate matter is also a by-product of coal combustion. Modern day utility boilers are usually fitted with electrostatic precipitators (ESP) to aid in the collection of particulate matter. Although extremely efficient, these devices are sensitive to rapid changes in inlet mass concentration as well as total mass loading. Without extreme care and due diligence, excursions or excessive soot can overload an ESP, resulting in high levels of PM being released.

Traditionally, utility boilers are equipped with sootblowers, which are lances that use, steam, water or air to dislodge and clean the surfaces within the boiler. The number of lances on a given unit ranges from several to over a hundred. Traditional sootblowing schemes involve fixed schedules for activating the blowers or the experience of the operators who manually activate various fixed sequences. Time based sequencing of sootblowers has been a traditional method employed by power plants, both domestically and abroad, to improve cleanliness within boilers. These systems are generally automated and are initiated by a master control device. In some cases, operators activate the systems manually on the basis of established protocols or generic procedures. These methods result in indiscriminate cleaning of the entire boiler or sections thereof, regardless of whether portions are already clean. Hence, traditional methods of sootblowing may be effective in assuring that a boiler is clean, but they fail to optimize the heat transfer rates therein, so as to maximize its operation relative to emissions and unit 
performance. In all cases, operators are challenged with a number of non-linear and conflicting objectives while ensuring that the boiler is stable and capable of meeting system dispatch requirements.

Simultaneously optimizing the objectives of NOx, PM and heat rate is difficult and unrealistic for a control room operator, even more so when that operator is also required to maintain control of the balance of the unit(s) equipment. The industry has recently been introduced to a number of "Intelligent" Rule-Based systems that derive their knowledge base from operator experiences, static plant design data, and general thermal principles. Whereas these systems are better than the traditional methods, they also fail to fully respond to the dynamic operation and condition of boilers. Rule-based systems are not readily adaptable to transitional operation of present day boilers, which, as a result of deregulation, are subject to volatile changes in operation and fuel types or blends. Furthermore, time or rule based systems are not the answer due to the complexity of the individual components, combinations thereof and the desire to satisfy multiple objectives in a dynamic real-time environment. Additionally, rule-based systems are only as good as the rules that drive them and established rules cannot accommodate the diverse set of operating conditions that may be encountered on a daily basis.

Neural networks have established themselves in a variety of industries to satisfy multiple goals or objectives in highly complex systems. These intelligent software systems have the ability to learn extremely complex relationships and trends between a great many input variables and then determine what control parameter changes are necessary to achieve the predetermined goals. Artificial Intelligence based systems are not designed to replace operators, but rather are an enabling tool. Recommended settings derived by neural networks and optimization systems can either be presented in the "advisory" form to the operator or can be integrated into the control logic on a closed-loop basis.

\section{Intelligent Sootblowing}

The goal of the project will be to develop a Neural Network driven Intelligent Sootblowing (NN-ISB) system module that proactively modifies the sequence of sootblowing in response to real-time events or conditions within the boiler, in lieu of time or general rule-based protocols. To date, the ability to intelligently blow soot while satisfying multiple and specific user defined objectives has not been integrated with an on-line, automatic and adaptive neural network driven sootblowing system. The NN-ISB module will provide an asynchronous, event-driven technology that is adaptable to changing boiler conditions.

Some of the basic technology components proposed for the project are commercially proven. However, the project also incorporates the use and application of several new or newly applied components and/or systems in conjunction with the NN-ISB system. The objective will be to reduce emissions and provide improvements in efficiency and reliability by employing synergistic approaches, which have not been possible with prior technologies. Some of the salient technologies planned for implementation during this project include, state-of-the-art heat flux and slag sensors, dual plane acoustic pyrometers, integration of boiler cleanliness and performance models with a neural network, and directional water cannons. 
Technology advancements in the past few years have resulted in the introduction of several diverse systems that could change the basic process of sootblowing. Specifically, robust temperature measurement products have emerged that allow localized measurement of fireside temperatures and heat transfer rates in both the furnace zone as well as the convection and backpass regions. The combination of these advanced measurement techniques coupled with today's high speed numerical processing allows for real time determination of tube fouling and levels of boiler tube cleanliness. Albeit limited in nature and scope, utilization of some of these technologies have seen some successes in their ability to improve the efficiency of the sootblowing process for US utility boilers.

Although prior testing and limited demonstrations have yielded some benefits in regard to NOx, PM and heat rate, these efforts have not been fully exploited in the development of a system that has the ability to understand, evaluate and optimize the process with multiple real-time objectives. The advantages of the knowledge capture and adaptive, counter-intuitive interactions with the NN-ISB system provides, the opportunity for a modular sootblowing optimization subsystem capable of significant operational benefits. Furthermore, since all utility boilers that fire pulverized coal and oils generate varying levels of soot and slag, the commercialization and benefits of this innovative technology has the potential to be readily and easily applied to a large population of power plants.

Independent manual sequencing of specific sootblowers has shown benefits in the area of heat rate efficiency improvement, NOx reduction and other areas relevant to efficiency and reliability. It is expected that additional, hard to quantify, gains will be realized in the areas of: tube erosion (minimized), auxiliary power consumption (minimized), perturbations in extraction steam flow (made more level), and particulate generation (managed to minimize impact on ESP). Of particular note, traditional sootblowers are high cost O\&M devices. Steam consumption rates of $30,000 \# / \mathrm{hr}$ are not uncommon and create substantial heat rate penalties. The maintenance costs are also very high considering the high pressures and temperatures, well in excess of 1000 degrees $\mathrm{F}$, that exist in many cases.

The NN-ISB system proposed herein will utilize the Neural Network technology from Pegasus Technologies, which has been implemented successfully for combustion optimization applications. This project shall use Neural Network based optimization, and state-of-the-art sensing and sootblowing equipment to direct the operation of the sootblowing systems in such a manner as to reduce NOx \& PM emissions, while concurrently improving the heat rate. Neural networks have not yet been fully implemented for ISB applications within the utility industry. Through these development activities, a NN-ISB will react to and take into account the heat distribution within the boiler, equipment life, emissions, and the overall cost of generating power. The objective is to develop a system to automatically determine the need for sootblowing in specific sections of a boiler and activate a blower or set of blowers for removing soot using adaptive, advanced control techniques. The net impact to the industry will be the demonstration of a commercially viable system that improves overall plant reliability and operations by reducing production cost, while also minimizing emissions. 


\section{EXECUTIVE SUMMARY:}

This project became effective after successful negotiation of the Cooperative Agreement related to the DOE award number DE-FC26-02NT41425, whose effective date was July 19, 2002. During this reporting phase, the equipment listed was installed on Big Bend Unit \#2. Salient installation notes are listed after each piece of equipment, which in certain instances may be unique to the Big Bend facility. All the major systems were started during this reporting period, except for the Pegasus neural network system, which is scheduled for the latter half of this year. Those components which have successfully been installed and are in various stages of final acceptance include;

\section{General Physics EtaPro 8}

Description: A heat rate performance monitoring system, which serves two primary functions. The first requirement involves taking baseline data of the unit to document "as-found" heat rates at various loads. The second function of the EtaPro system is to provide real time boiler cleanliness information to the neural network system.

Status: This system was installed at the beginning of this project. No significant problems have been encountered during the installation of this system, however it has been discovered that despite corrections for cleanliness the system has not been able to provide valid data to support this system. Accordingly, the cleanliness factor portion of the EtaPro is not being used.

\section{$\underline{\text { SBC } 1000 \text { Sootblower Control System }}$}

Description: The SBC 1000 provides a bi-directional link between the actual sequencing panel and the plant DCS.

Status: The system was installed during the 2002 outage. The system provides graphics for all sootblowers and is the "hub" for data transfer to Pegasus, as shown in the sketch below. Custom screens for the AccuTemp system and slag sensors have been developed. Communications protocols between the SBC and the water cannon system have been successfully implemented, however some minor refinements are being implemented.

\section{$\underline{\text { Slag Sensors }}$}

Description: Eight slag sensors utilizing electrical conductivity as the method for determination of slag accumulation are included. Two of the sensors have been installed in close proximity to the heat flux sensors to derive comparative data while the balance will be installed in between the heat flux sensors to gather additional condition assessment data. 
Status: Two sensors were installed approximately at the 79' elevation about two (2) feet from the Clyde-Bergerman heat flux sensors. An independent report has been issued which indicates that the slag sensors do not have a repeatable correlation with the heat flux sensors.

\section{$\underline{\text { AccuTemp Acoustical Pyrometer Grids }}$}

Description: Two grid networks were installed, one at the furnace outlet plane and the other at the economizer outlet plane. The information derived from this system shall be used in conjunction with the stations existing thermal couple data on various high temperature circuits and the boiler cleanliness module to more accurately determine the slag conditions in the convective portion of the furnace.

Status: Three of four amplifiers have had problems with reliability, therefore the supplier, Solvera, has changed suppliers and has supplied new amplifiers under warranty to improve the systems effectiveness. The rootcause of the failures appears to be related to no oilers being included as part of the original scope. Based upon the neural network modeling requirements and negotiations with Pegasus, Solvera, and Tampa Electric the AccuTemp system at the economizer plane has been eliminated from the neural network effort. The furnace outlet AccuTemp system is being modeled for neural network control.

\section{Water Cannons \& Sootblowers}

Description: Four (4) water cannons were installed complete with Clyde-Bergermans Smart Sensor ${ }^{\mathrm{TM}}$ control system, which includes sixteen (16) heat flux sensors. The supplier noted that the water cannons have the capability of accurately cleaning the waterwalls to achieve various levels of cleanliness. Prior to implementation of the neural network system, the system shall be operated using standard operating procedures. The current work also includes the addition of several conventional sootblowers in the convective region to allow for strategic cleaning.

Status: The upgrades to the water cannon seal air system and refractory of the boiler connections have failed again during this reporting period. CB has supplied sixteen (16) new heat flux sensors, which were recently installed. One of the new sensors has fialed during this reporting period. The water cannons were evaluated for their effectiveness to reduce NOx in Big Bend Unit 2. The results indicated that little to no reduction in NOx was achieved while using the water cannon system. The ability of the water cannons to effectively clean the target areas is being evaluated. The results of the NOx testing is shown in Results and Discussion. 


\section{Pegasus/Neural Network}

Status: Pegasus has installed both the first and second phase neural network models. The second stage is being field tested to ensure that it is fully compatible with the stations operational and safety requirements. A detailed listing of the activities performed by Pegasus during this reporting period is provided in the appendix.

Project meetings were held on August 27, 2002 and Feburary 19, 2003 including various Tampa Electric personnel, Pegasus Technologies, Clyde-Bergerman, General Physics, and Solvera. The focus of these meeting were to ensure that all the requisite components of the project had been identified and to establish a network for communication of data. The project participants concluded that the flow of information amongst the various existing systems and new systems for this project should take the form shown in the illustration below. Communications protocols have been modified several times throughout the process as a result of "lessons" learned between the various systems. The details of this effort will be addresses in the project "Design Report”.

Figure 1 - Proposed Communications Network

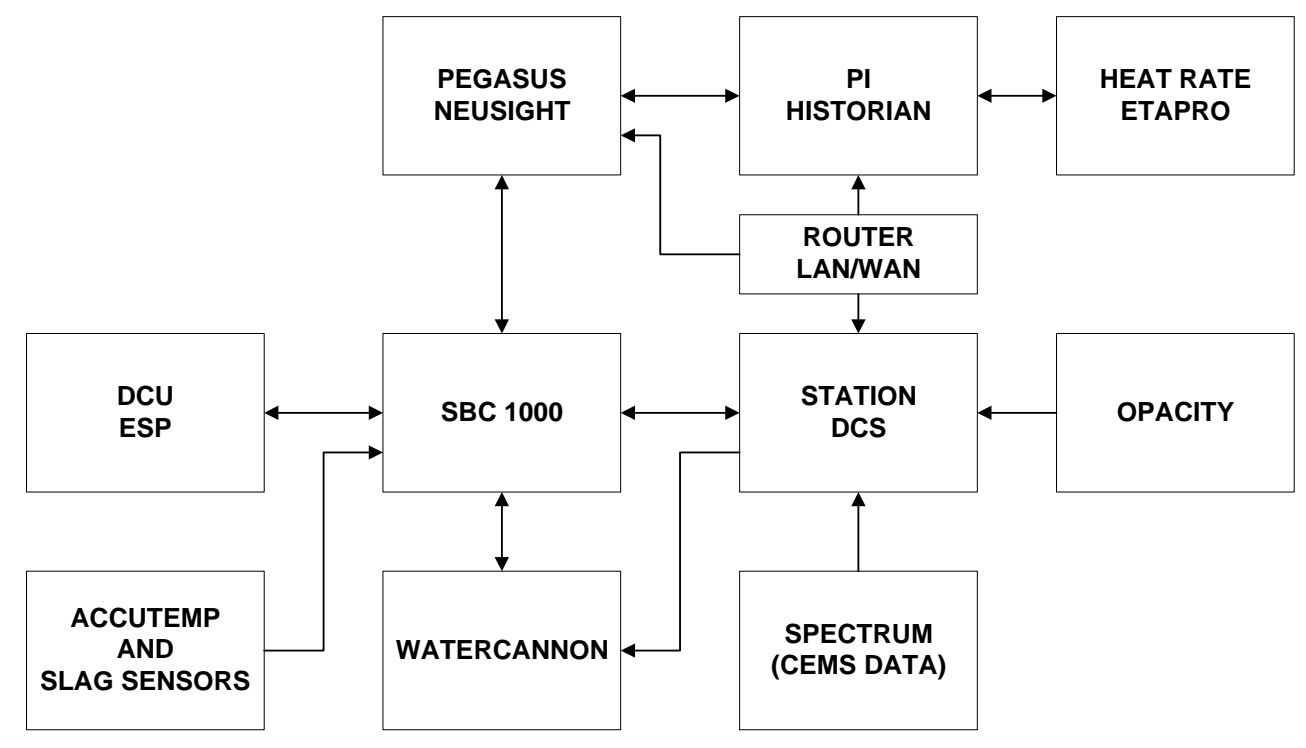




\section{EXPERIMENTAL:}

The slag sensors are operational and data is being collected. Trend comparisons are currently being performed against an adjacent heat flux sensor. The early results of that effort indicate that there is a correlation between the two sensors. Further evaluation of the data is required to ensure that the apparent correlation is related to heat flux rather than other variables. 


\section{RESULTS AND DISCUSSION:}

Pegasus initiated parametric testing at Big Bend Unit \#2 during the second and third quarter of 2003. The purpose of parametric testing was to generate data with reasonable and safe variations outside the normal operating regime (standard operating pattern based on DCS curves) of the unit. Such data is essential for building a neural network model encompassing a variety of boiler operating conditions, which can then be used to best predict and optimize the process.

Using a variety of trending tools Pegasus has analyzed the data collected. They have highlighted some areas of interest where process optimization opportunities exist for both NOx reduction and boiler efficiency improvement. The following preliminary observations illustrate some of the potential results which can be obtained under Neusight control. More testing is necessary to further confirm the repeatability and validate some of the data collected to date.

\section{Observations:}

- Figure \#2 and figure \#3 show the boiler base-loaded at a steady state load around 400MW with steady $\mathrm{O} 2$. With these process settings a NOx delta of approximately $8 \%-10 \%$ is realized. This difference is not correlated to O2, fuel changes or other evident events. Note that the load increased slightly, O2 decreased, while NOx decreased dramatically.

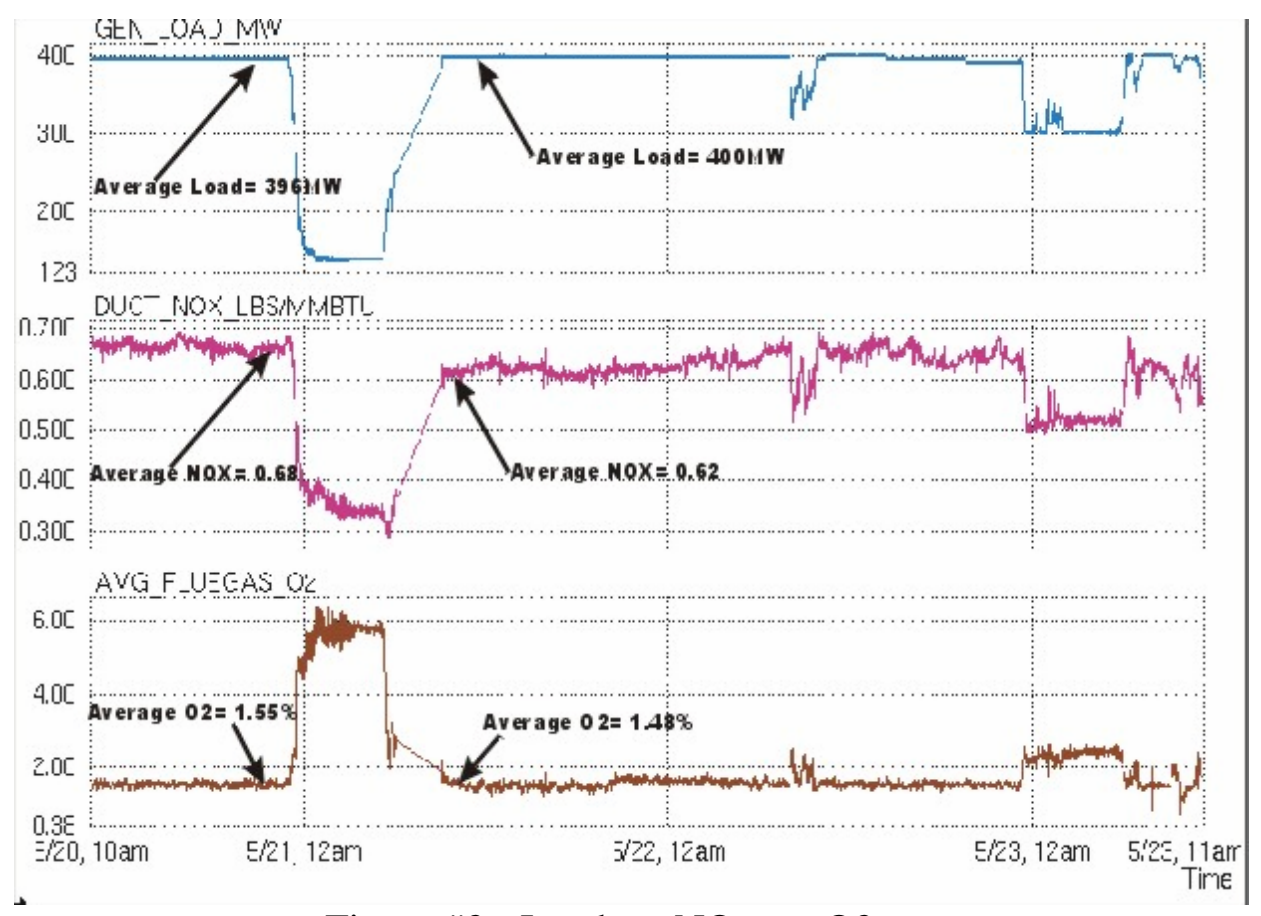

Figure \#2 - Load vs. NOx vs. O2 


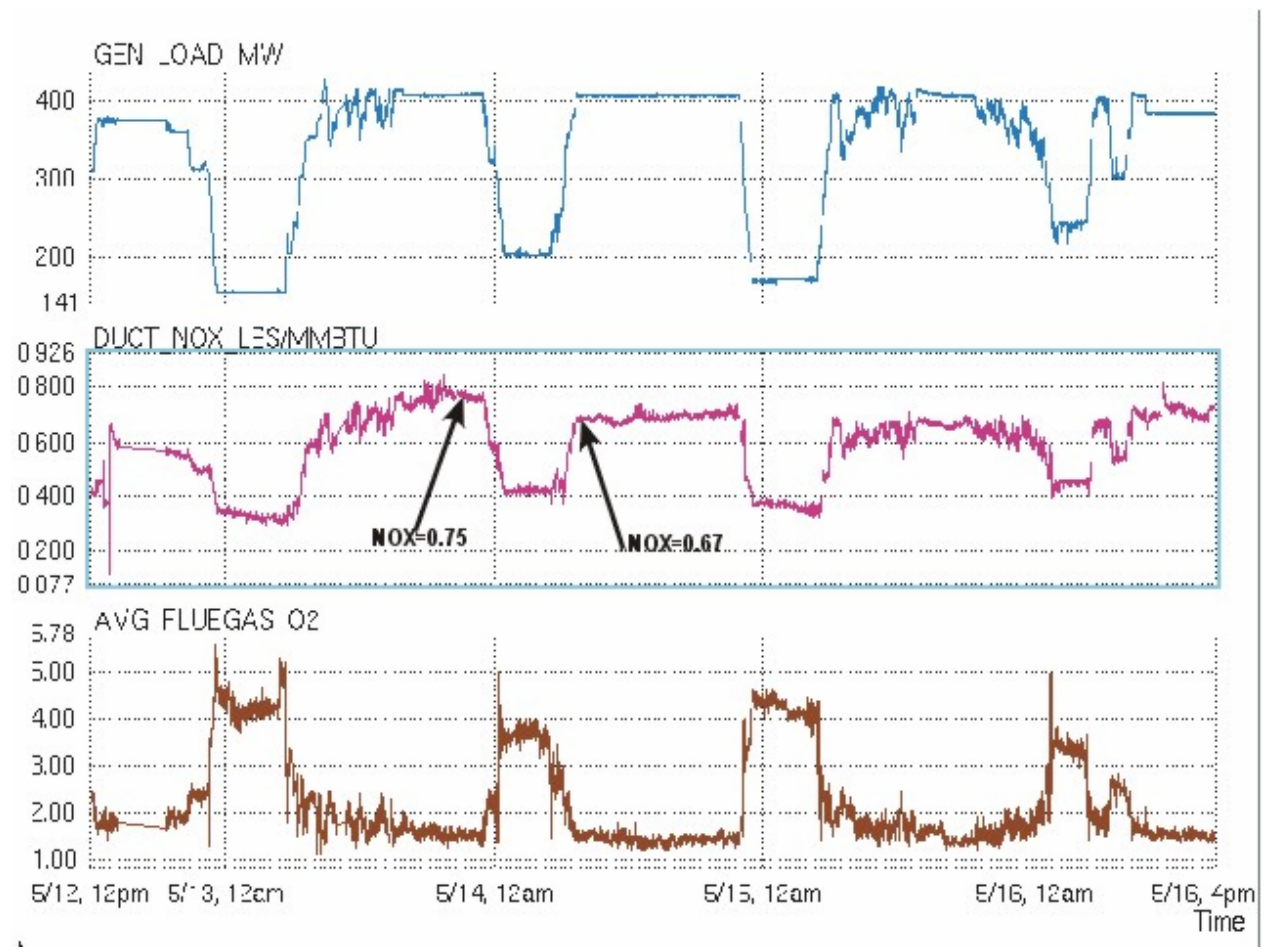

Figure \#3 - Load vs. NOx vs. O2

- Figure \#4 and figure \#5 show how the "D" sootblowers are related to NOx. D1 is representative of " $\mathrm{D}$ " series blowers and is also the last to be energized. Load was steady at around 400MW and also O2 (not showed) was steady at around 1.5\%. Boiler efficiency also improves after a short period following sootblowing. Note that NOx increases after a long elapsed time without blowing the "D" sootblowers while remaining about the same when the duty cycle of blowing was increased.

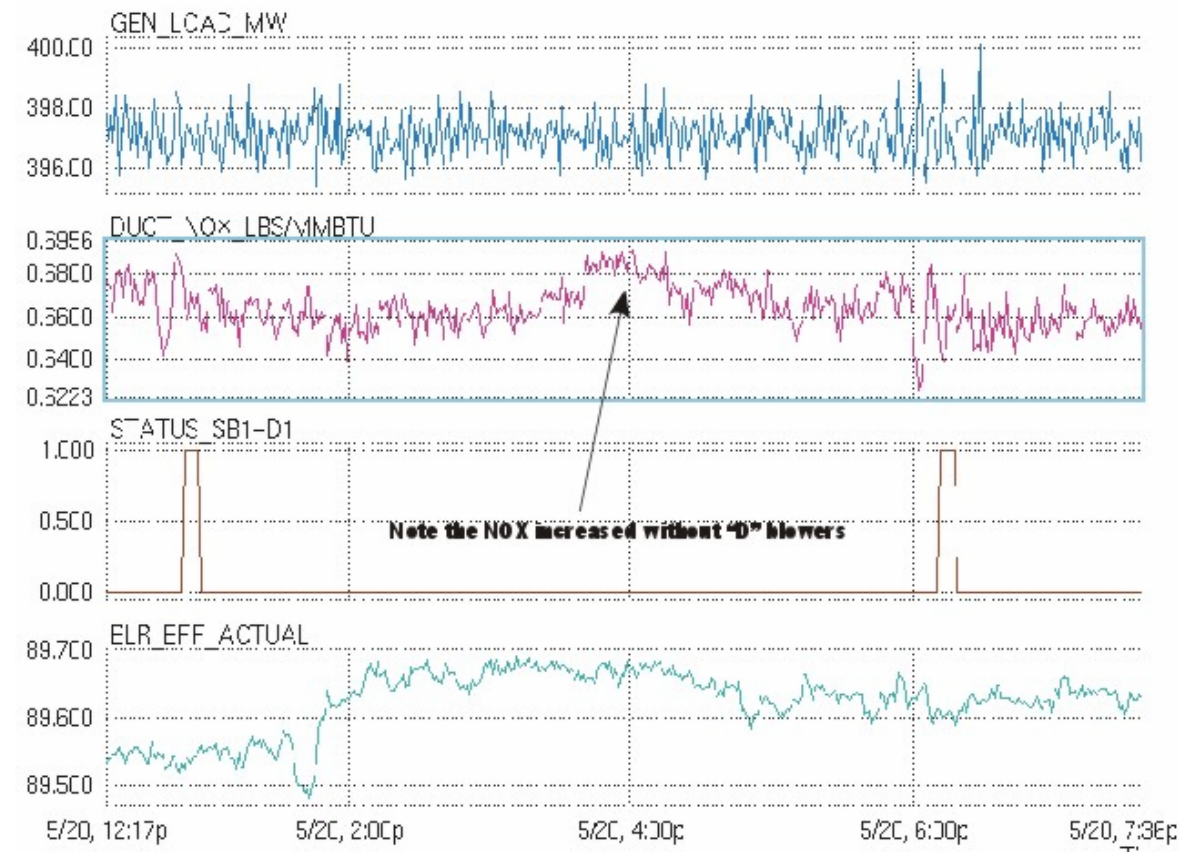

Figure\#4 - NOx vs. “D” Blowers vs. Heat Rate 


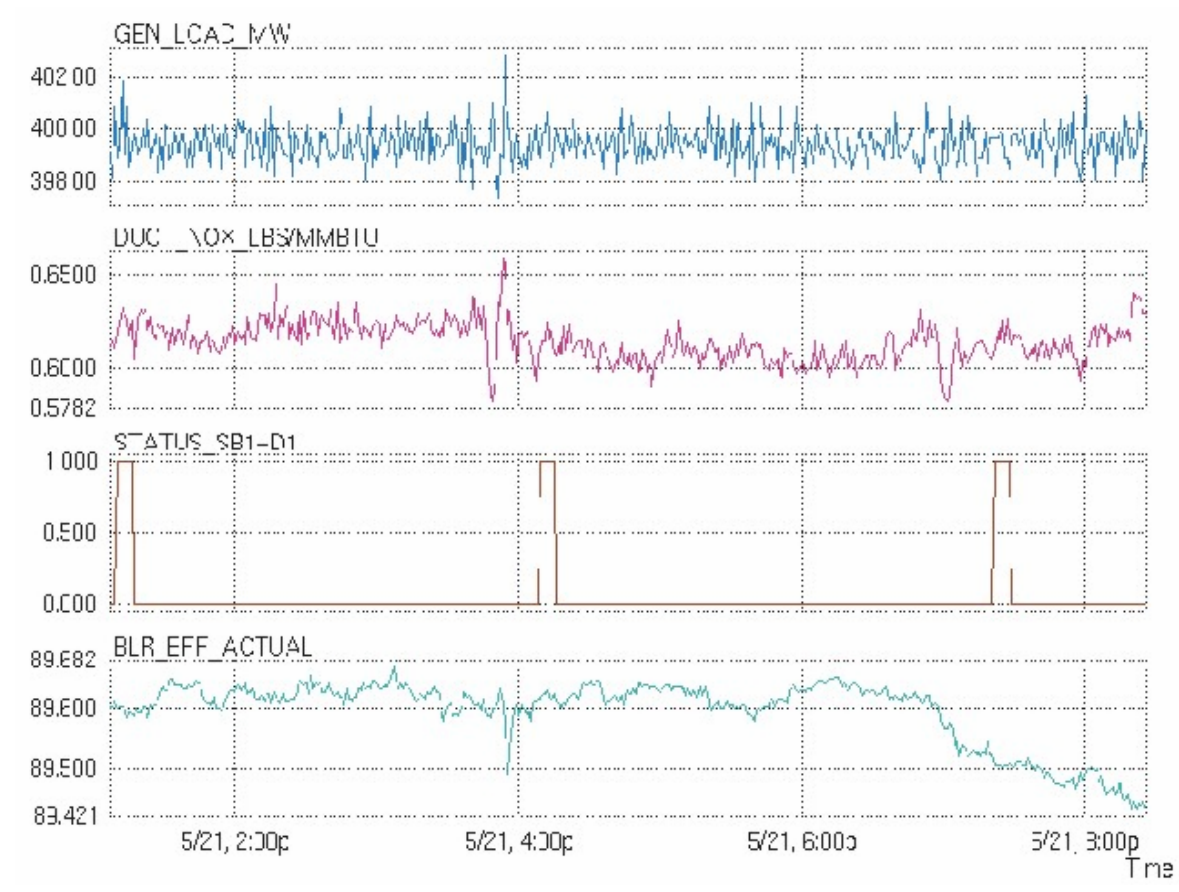

Figure \#5 - NOx vs. "D” Blowers vs. Heat Rate

- Figure \#6 show sootblowing effects on NOx at low load operation. Again, NOx is reduced by sootblowing without changing any combustion parameters.

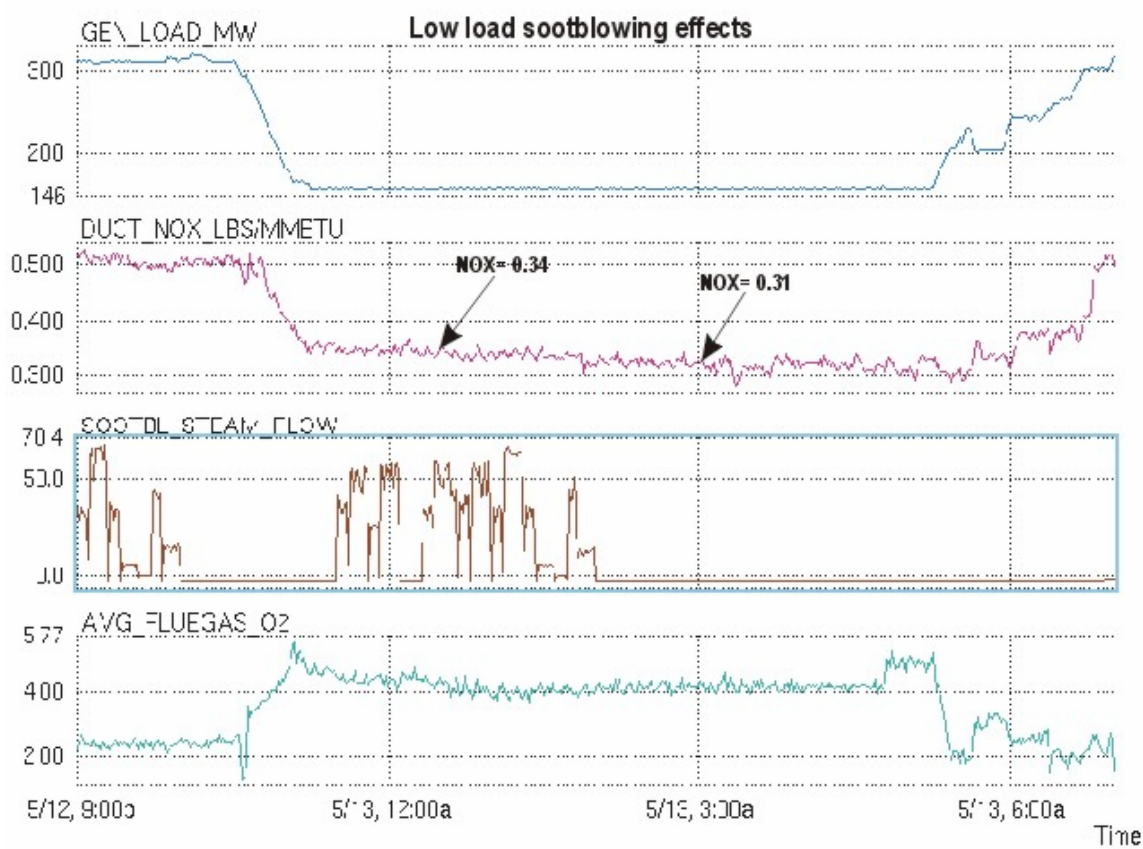

Figure \#6 - Impact of Low Load vs. NOx with Sootblowers

- Figure \#7 and figure \#8 show affects of "E" blowers. The "E" blowers tend to produce a disturbance in NOx spikes, increase NOx and negatively affect boiler efficiency. The unit was based loaded and had steady O2. E7 blower showed in the trend is the first of the eight 
blowers of the E series. Note that two"Es" blowers were out of service during the testing (E6and E4).

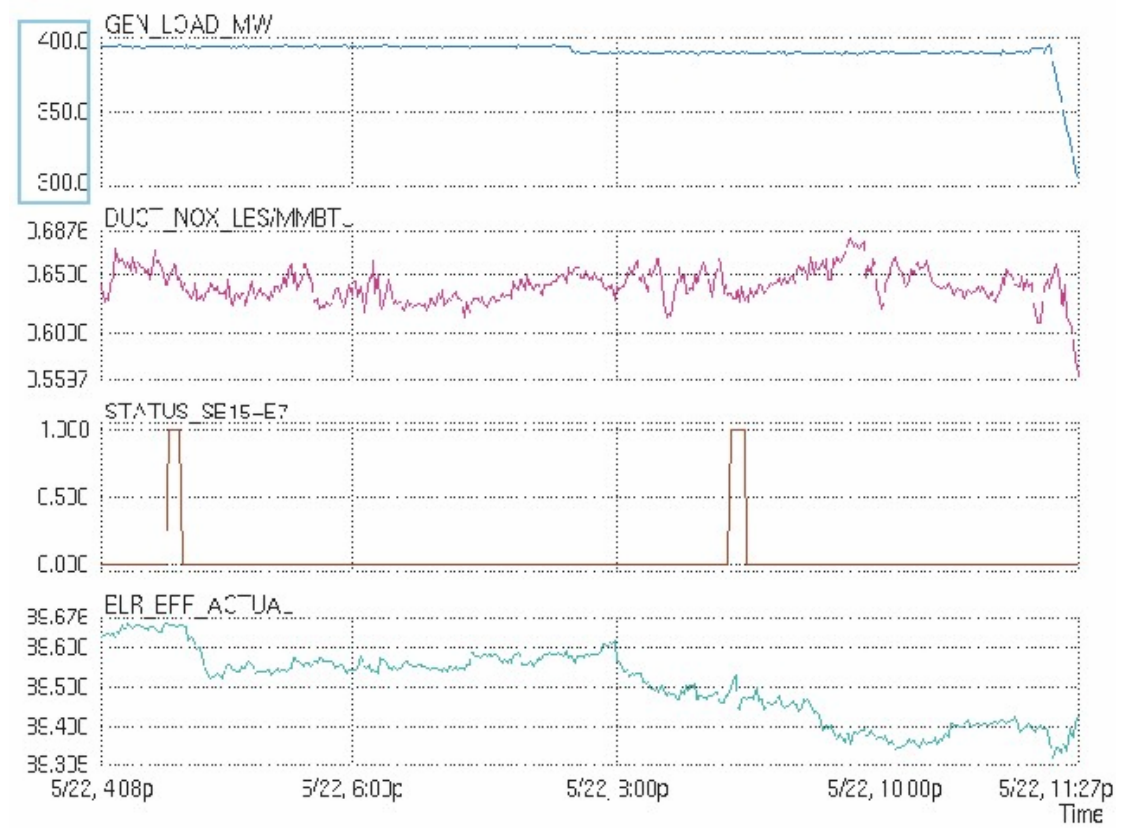

Figure \#7 - NOx vs. “E” Blowers vs. Heat Rate

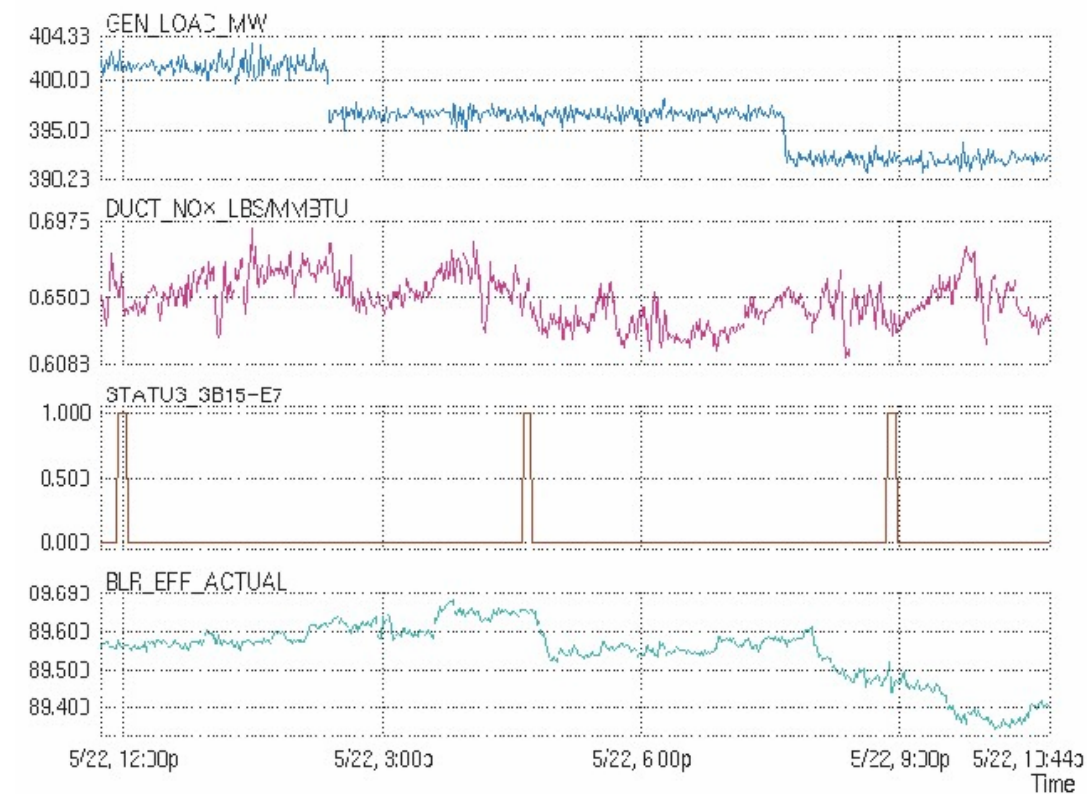

Figure \#8 - NOx vs. "E” Blowers vs. Heat Rate

- Figure \#9 and figure \#10 shows the direct effect of $E$ series blowers on the reheat parameters. Note that only F1, G1 and G4 sootblowers were available on the upper rear pass. No direct effect is correlated to the rear pass blowers only the Es blowers seem to make a clear difference on the reheat DP. Figure\#9 shows the impact of the E series and D series sootblowers on the steam attemperation and reheat steam temperature. Again no impact is noticeable from the rear pass blowers. 


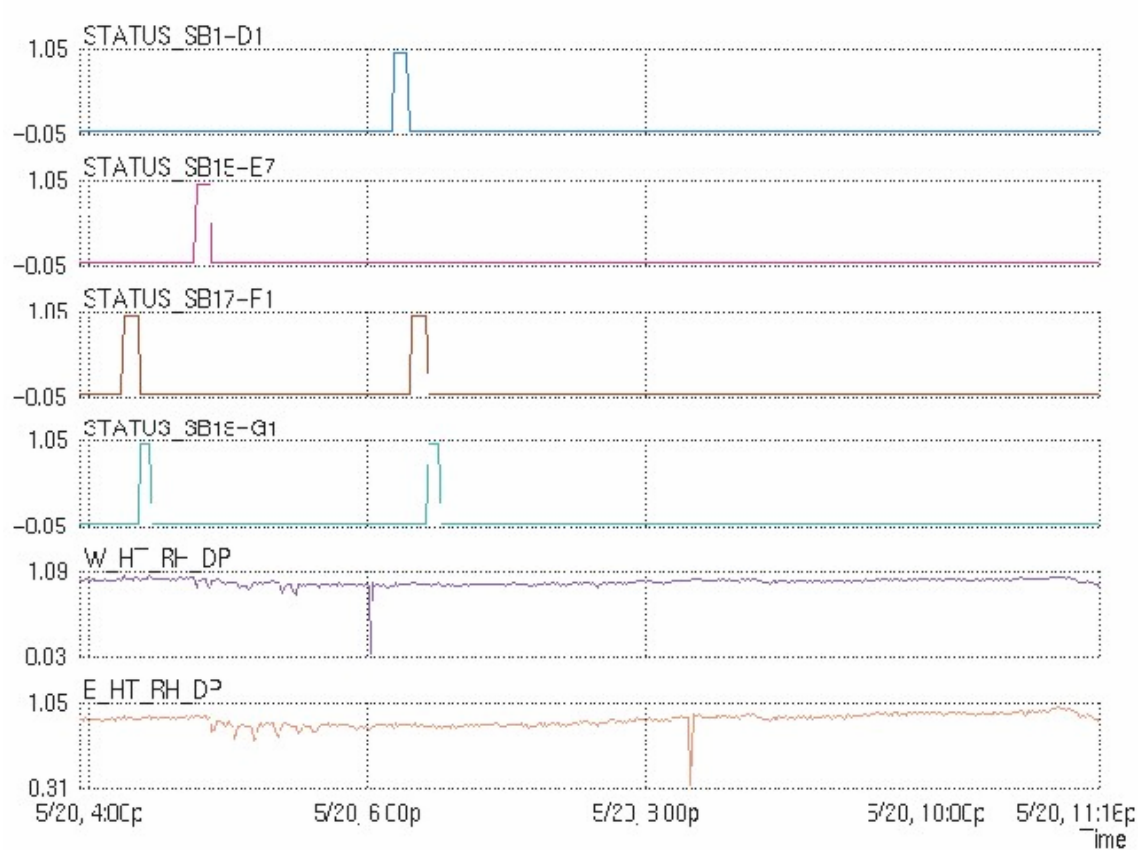

Figure \#9 - Reheater Performance vs. “D,E,F,G” Sootblowers

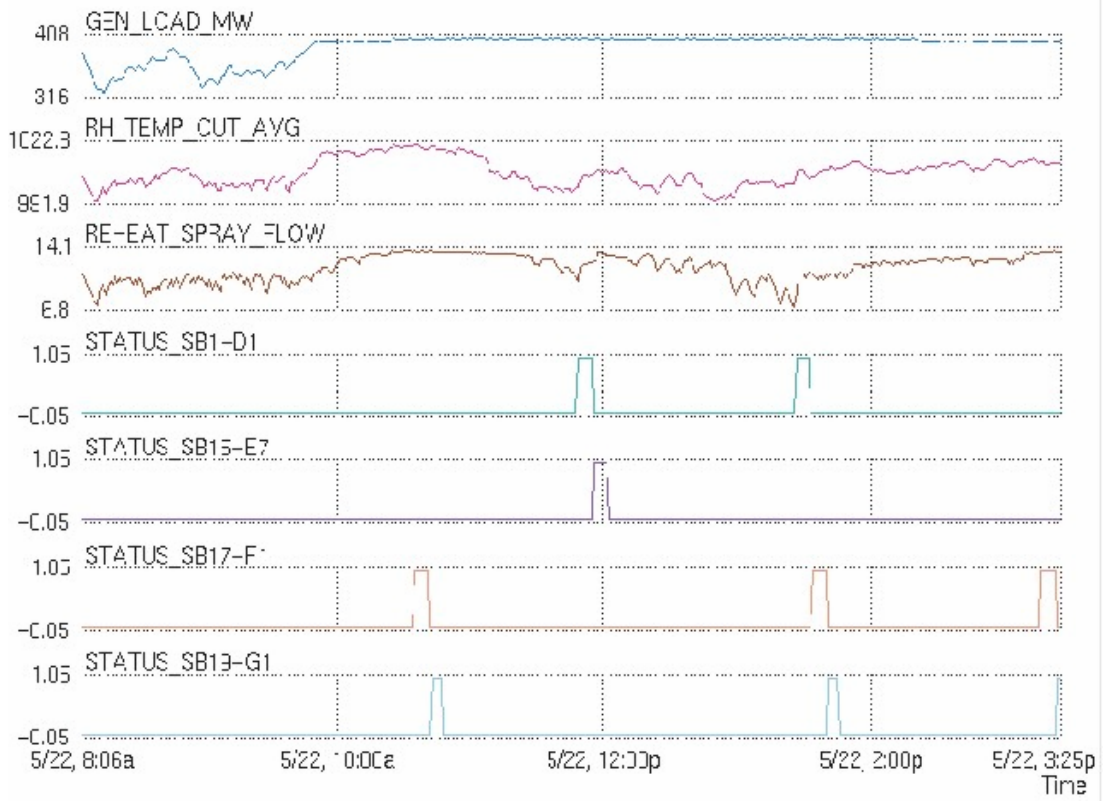

Figure \#10 - Reheater Performance vs. “D,E,F,G” Sootblowers

Additionally testing was performed on mill temperatures and mill levels. Mill temperatures set points were stepped from 155 deg $\mathrm{F}$ to 145 deg $\mathrm{F}$ with 5 deg $\mathrm{F}$ variation. All combination settings were tested in order to gather training data for the neural-network. Some preliminary testing was also conducted whereby mill level varied from $2.5 "$ to 4 ". 
- Figure \#11, figure \#12 and figure\#13 show the boiler base-loaded at a steady state load of $397 \mathrm{MW}$. The $\mathrm{O} 2$ was approximately $1 \%$ and NOx was averaging $0.72 \mathrm{lbs} / \mathrm{mmbtu}$. Mill level was changed from 3" to 4". As the mill level adjusted to the new setpoint, various boiler combustion changes occurred, 1) Fuel master setpoint increased to meet the extra air demand required to maintain mill temperature, 2) Boiler $\mathrm{O} 2$ increased $0.5 \%$ due to extra primary air, and 3) NOx, decreased approximately $5 \%$ to $0.68 \mathrm{lbs} / \mathrm{mmbtu}$.

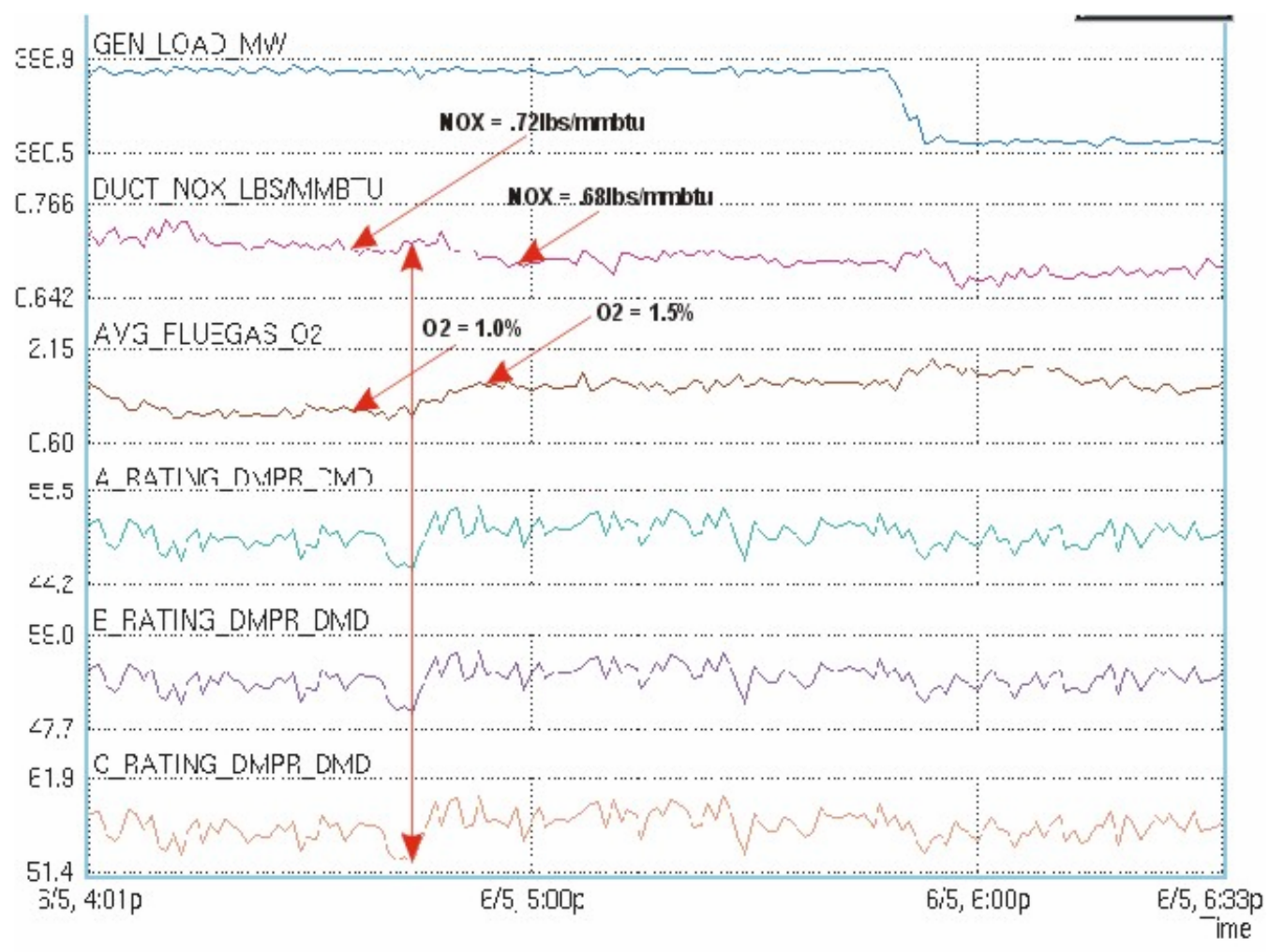

Figure \#11 - Mill Operation vs. NOx 


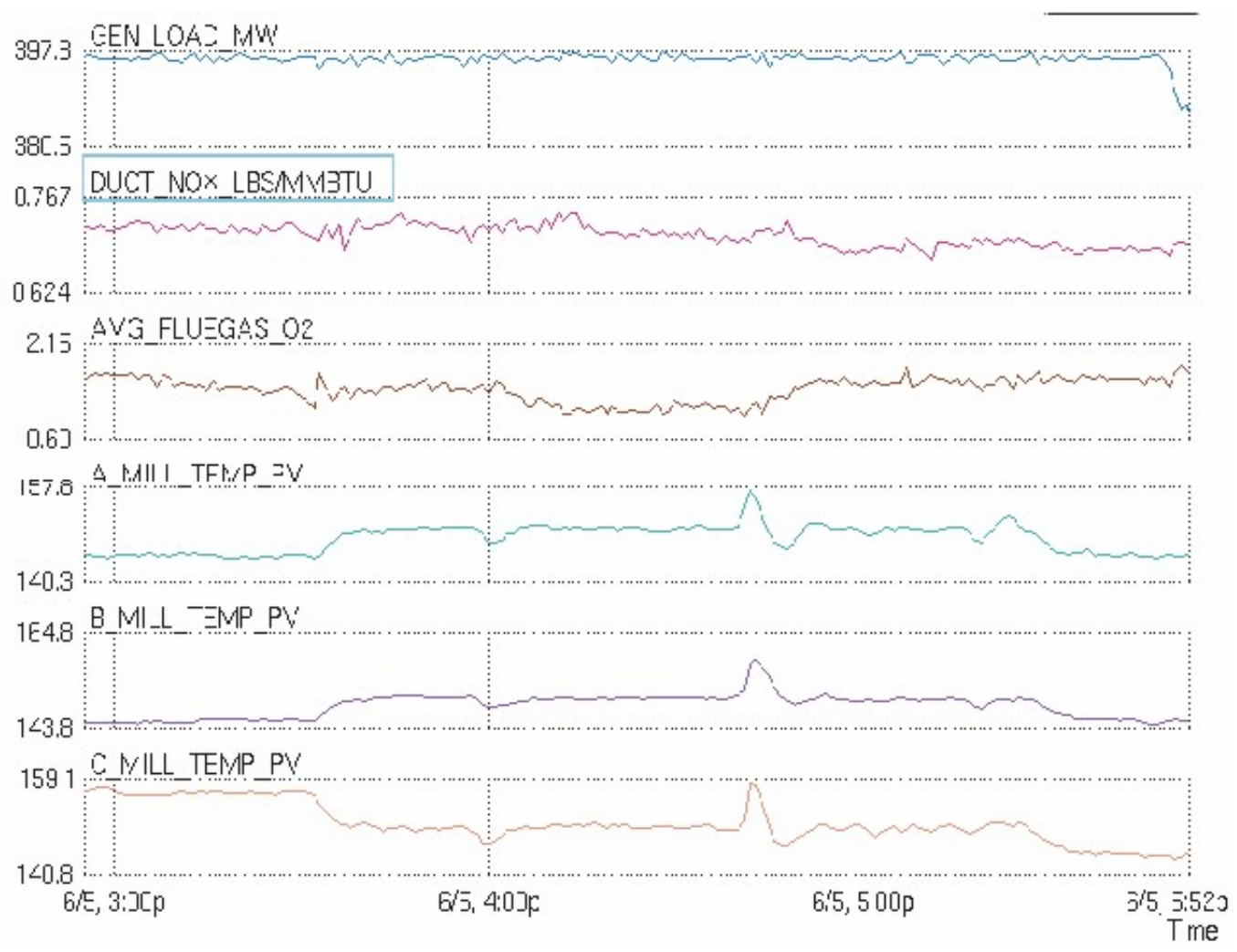

Figure \#12 - Mill Operation vs. NOx

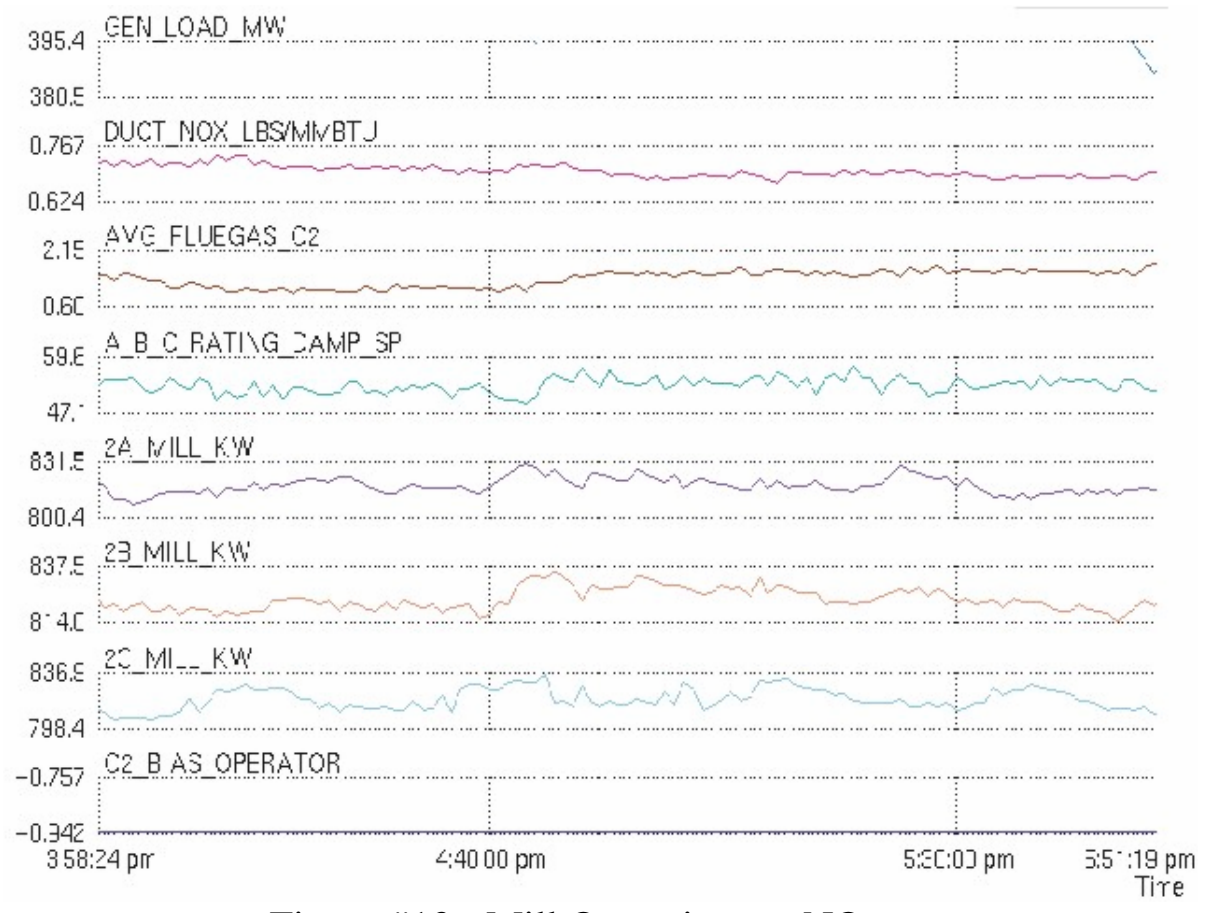

Figure \#13 - Mill Operation vs. NOx 
- Figure\#14 shows the impact of mill temperature on NOx. With steady load and all combustion parameters held constant, all three-mill temperatures were dropped to around 146deg F. The NOx decreases slightly, however NOx increased much more prominently when two out of three mill temperatures are increased to $155 \mathrm{deg} \mathrm{F}$.

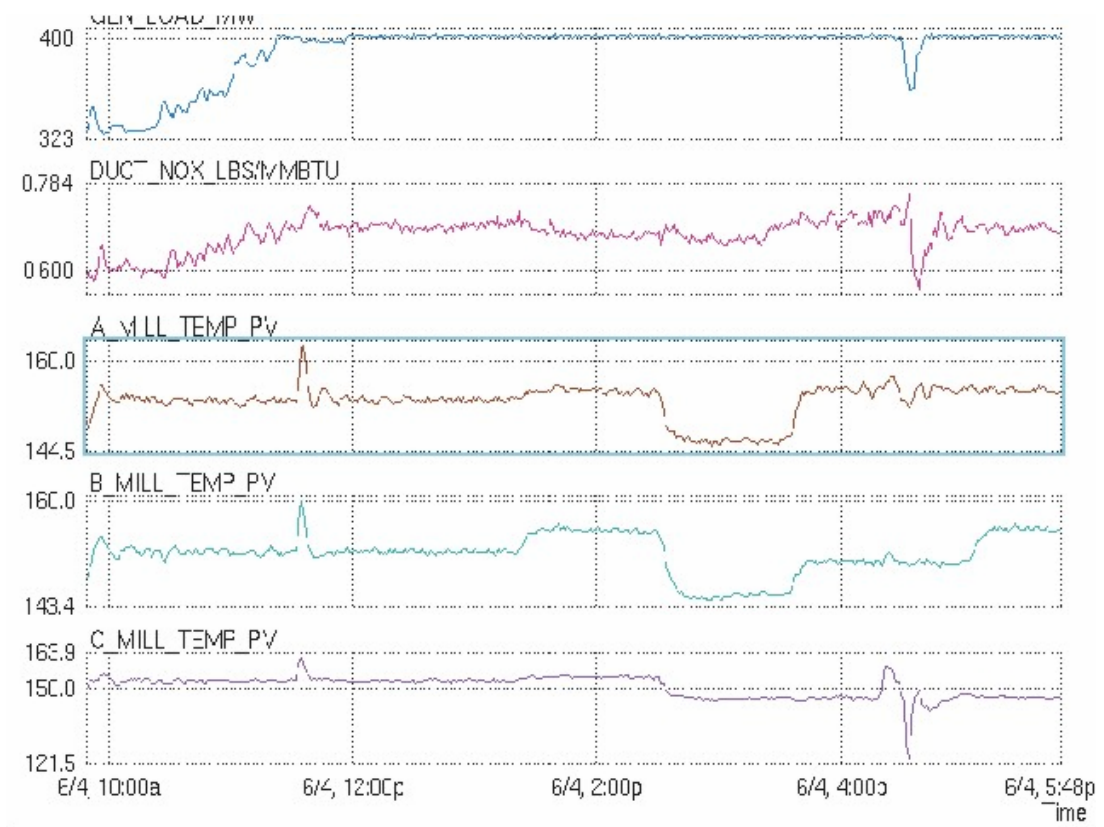

Figure \#14 - Mill Outlet Temperature vs. NOx

Subsequent to the foregoing test results, additionally testing and modeling was performed to determine relationships between the various sootblowers as they relate to NOx generation and boiler efficiency. These graphs were generated by holding the excess $\mathrm{O} 2$ levels at a constant, in reality numerous sets of graphs could be produced which depict the vast number of operating conditions that the boiler can be subjected to during normal operation.

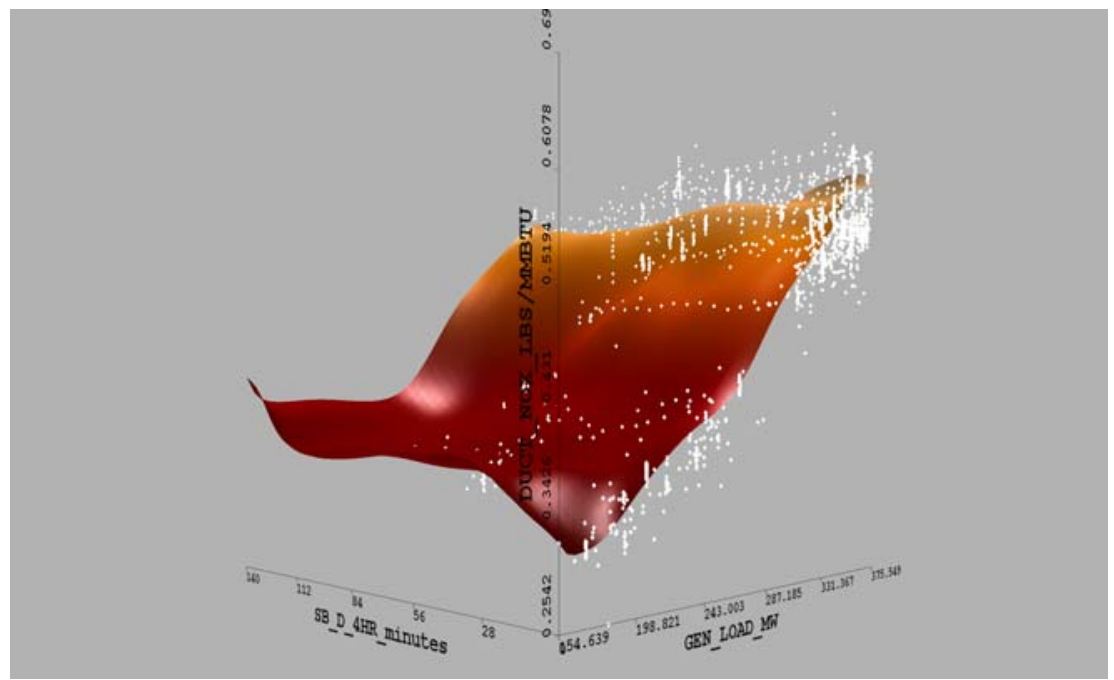

Figure \#15 - NOx vs. Load vs. Sootblower Duty (Group D) 


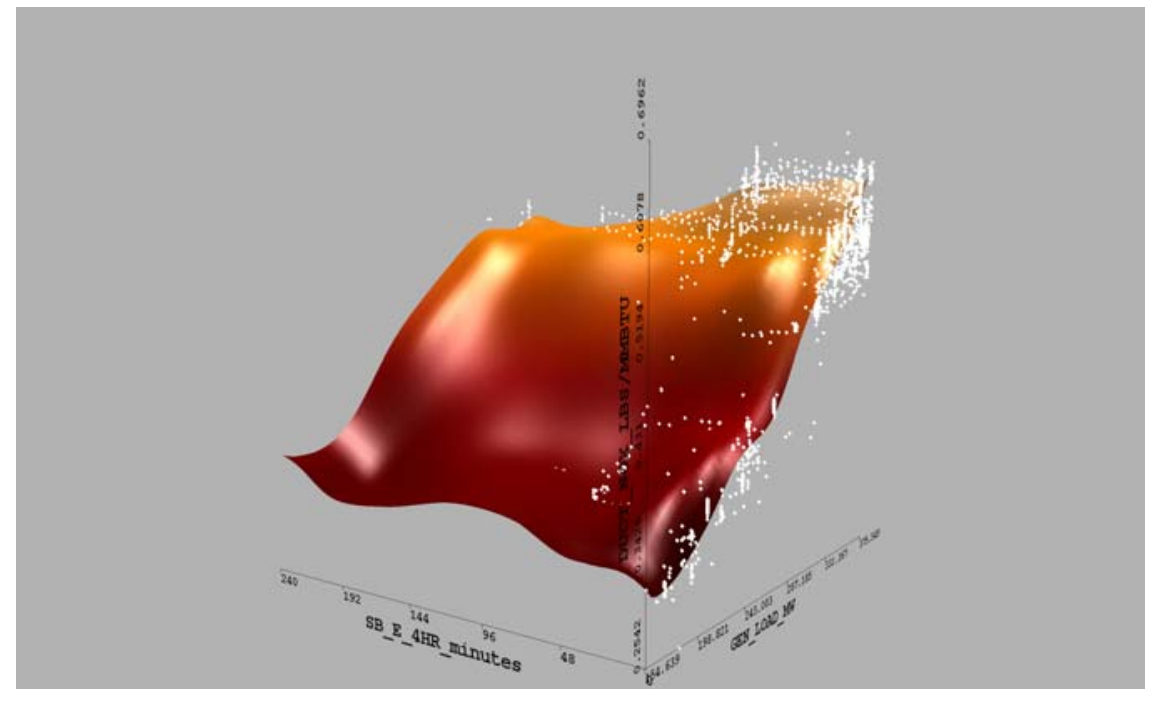

Figure \#16 - NOx vs. Load vs. Sootblower Duty (Group E)

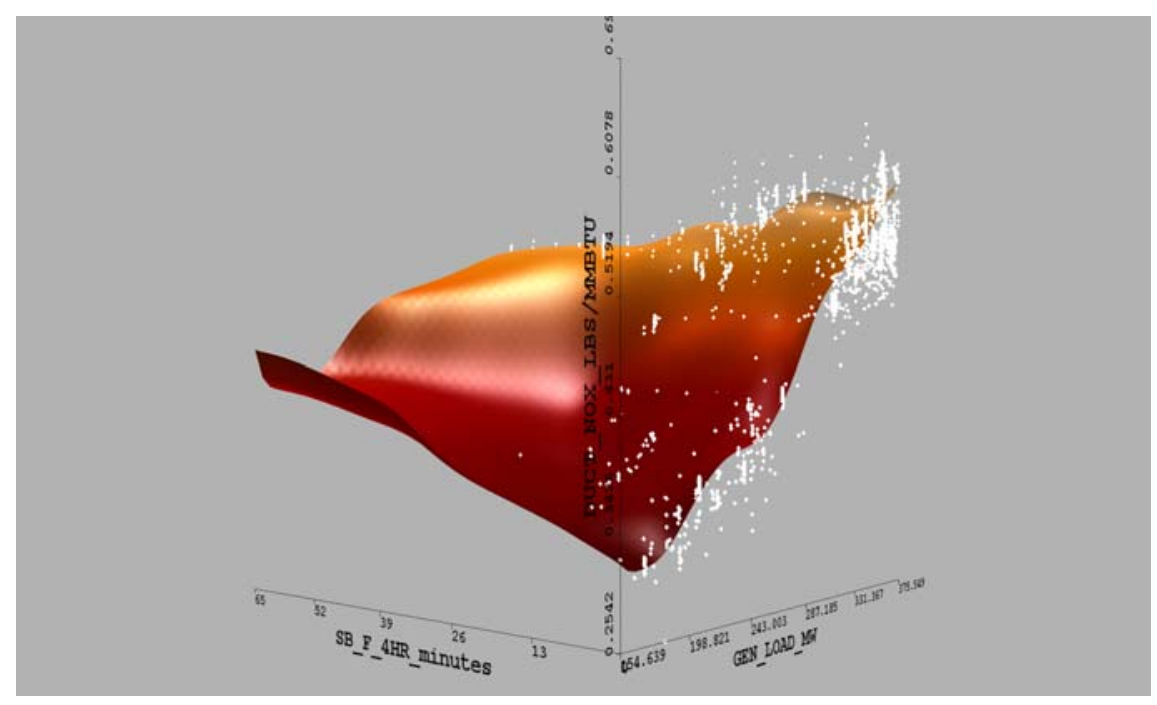

Figure \#17 - NOx vs. Load vs. Sootblower Duty (Group F) 


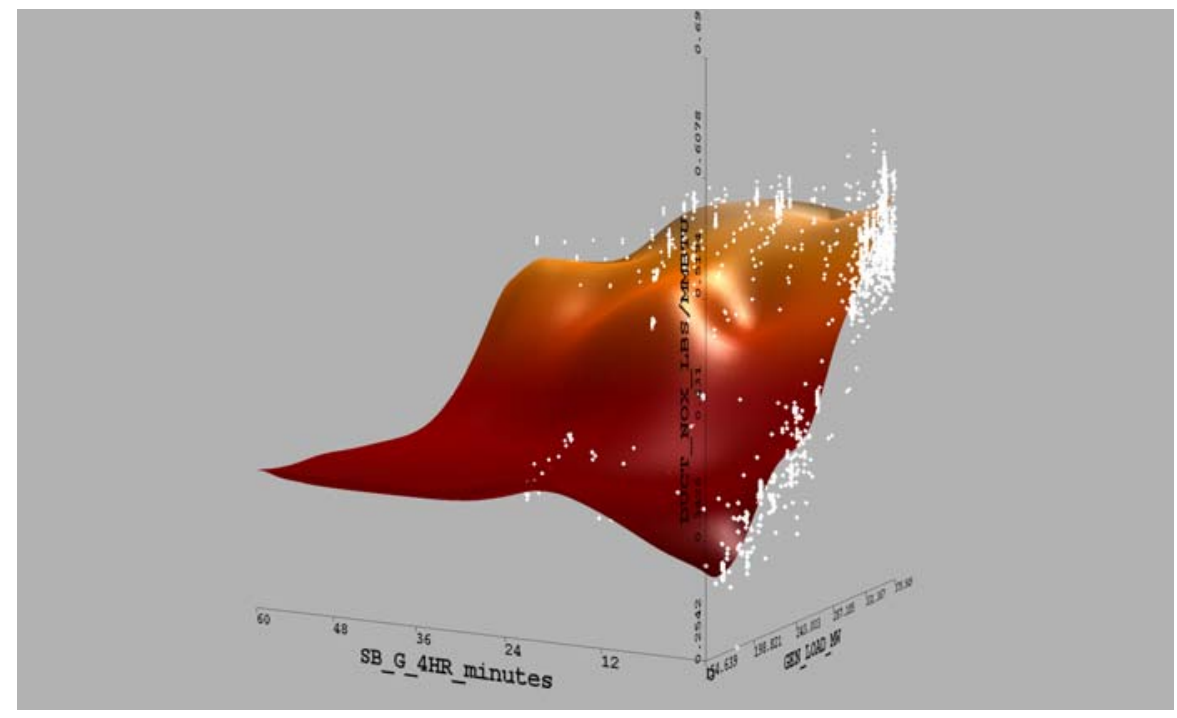

Figure \#18 - NOx vs. Load vs. Sootblower Duty (Group G)

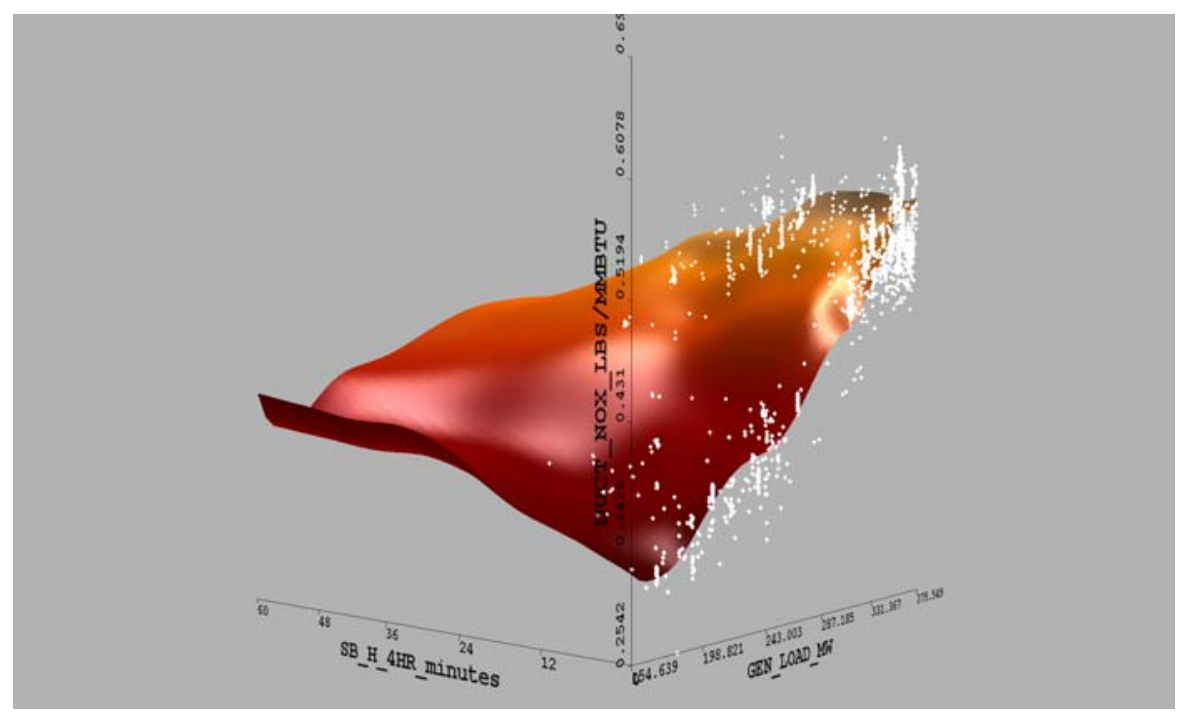

Figure \#19 - NOx vs. Load vs. Sootblower Duty (Group H) 
Figures \#15 - \#19 illustrate the relative impact of each sootblower group as it relates to NOx generation. Sootblower groupds " $D$ " and " $E$ " are located within the radiant section of the boiler and therefore have the greatest ability to control NOx generation. As the sootblower groupds progressively move further back into the convective passes, the ability to affect NOx generation is significantly reduced. The graph ordinates indicate the boiler load, NOx production in lbs/MMBtu and the duty cycle of each sootblower group within a four-hour period. As reflected in the graphs, there exists various toughs or valleys wherein operation of the sootblowers within those regions will minimize NOx production. Again it must be emphasized that these graphs are illustrative of a series of parametric tests wherein numerous variables were held constant. Accordingly, the development and application of rule based systems based upon this single planar surface would not capture the benefit of neural network controlled systems.

Figures \#20 - \#24 plots are similar to \#15 - \#19, except the Z axis is boiler efficiency. The same data set was used (with data screened for "apparent $\mathrm{O} 2$ bias of -1). The range on the $\mathrm{Z}$ axis is same for all plots: $89.34 \%$ to $90.82 \%$. Most plots (each sootblow group) show that along a given load line, the efficiency generally drops at low loads with sootblowing (sometimes after an initial rise), but increases at high loads with increased sootblowing. The effect is more pronounced for the convective area blowers (F, G, H).

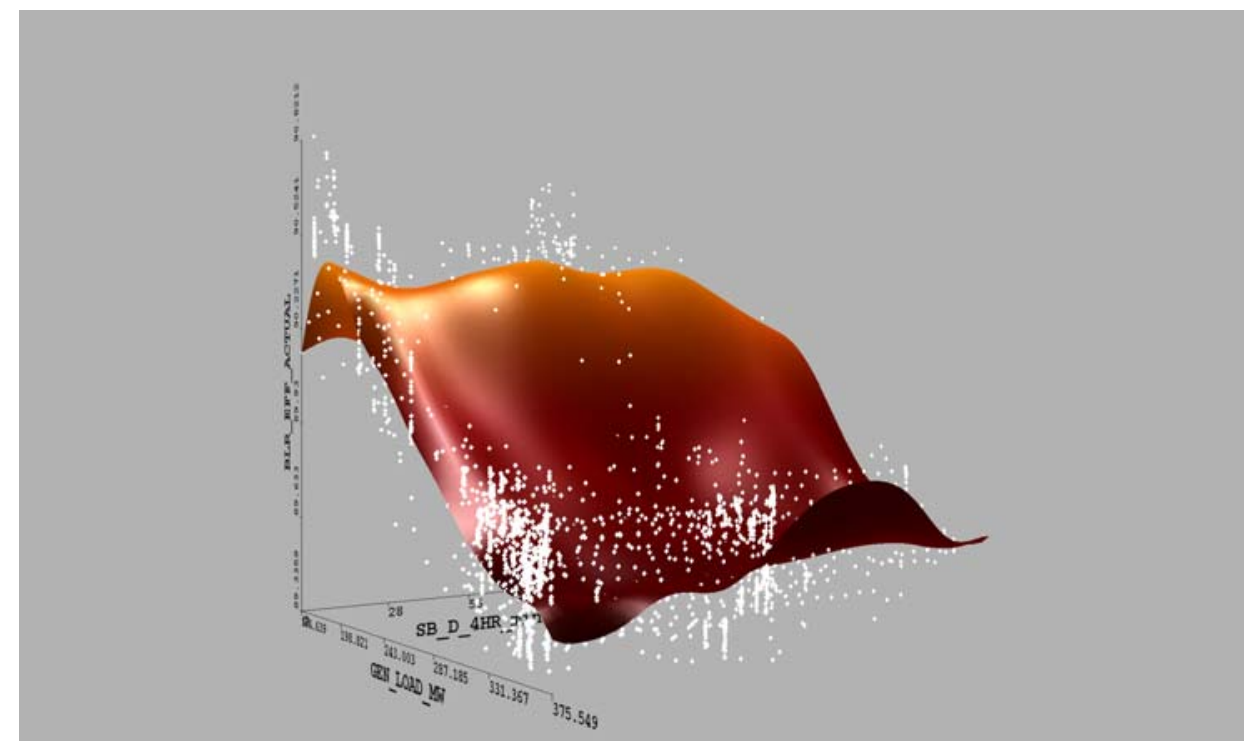

Figure \#20 - Boiler Efficiency vs. Load vs. Sootblower Duty (Group D) 


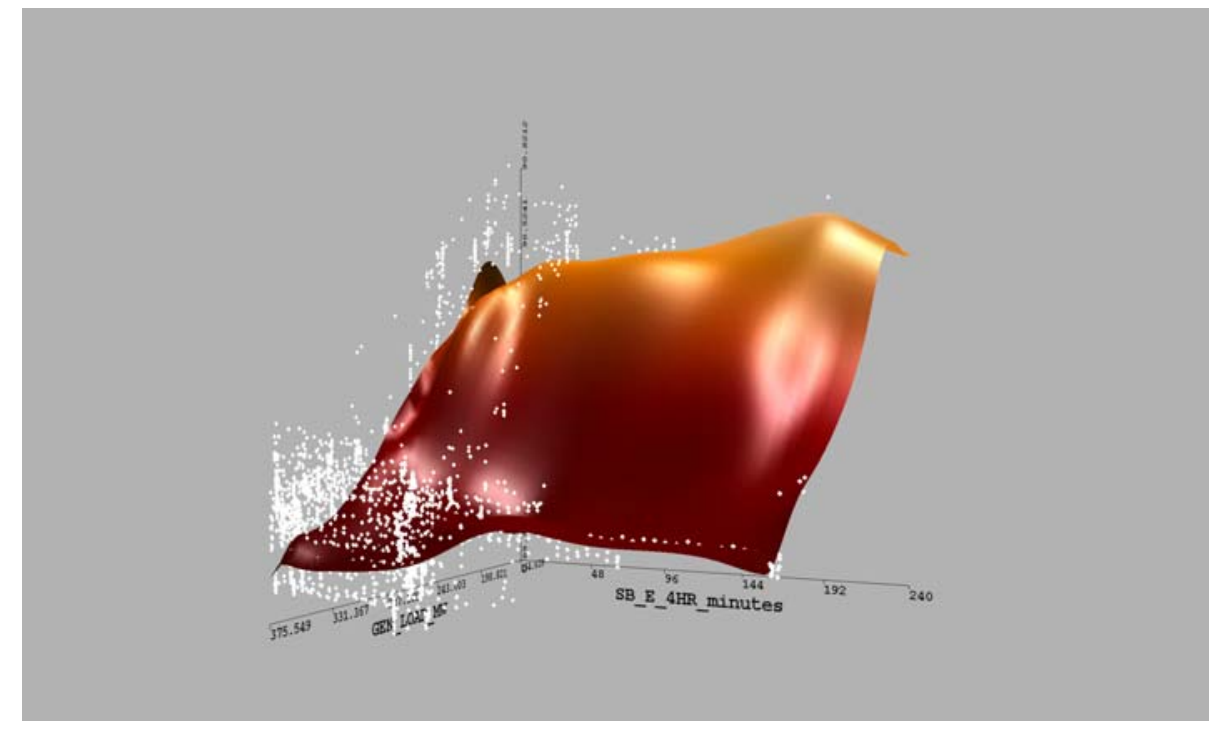

Figure \#21 - Boiler Efficiency vs. Load vs. Sootblower Duty (Group E)

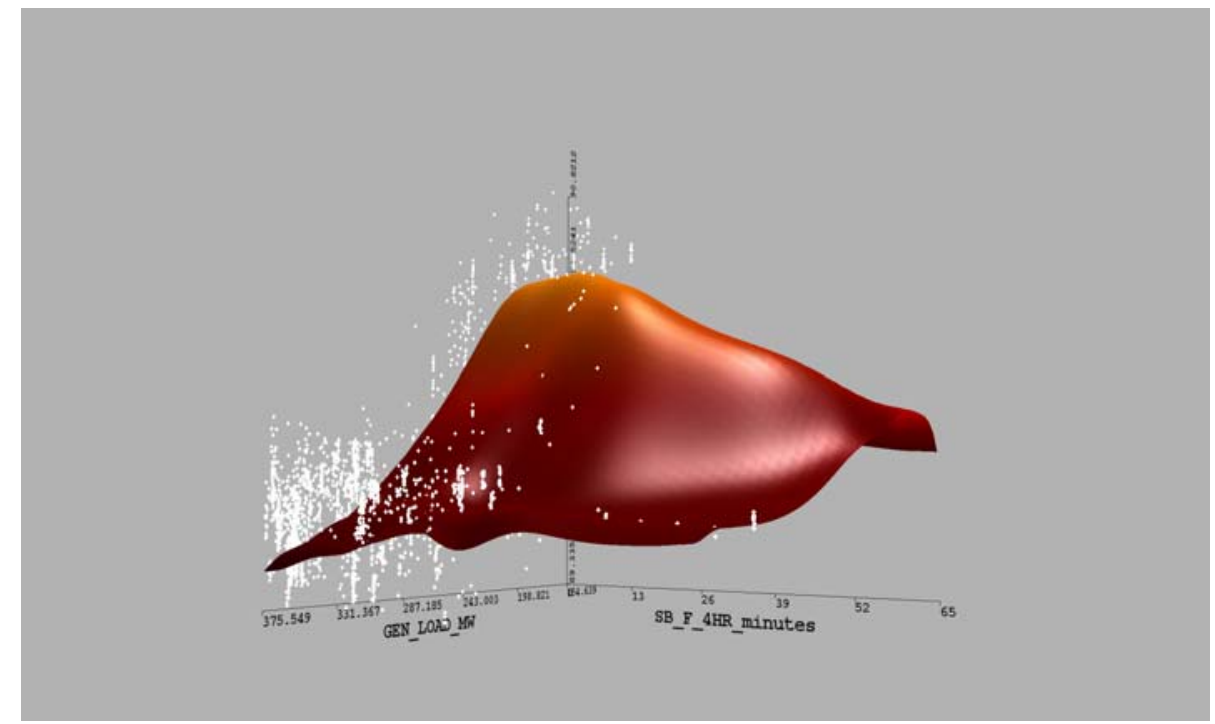

Figure \#22 - Boiler Efficiency vs. Load vs. Sootblower Duty (Group F) 


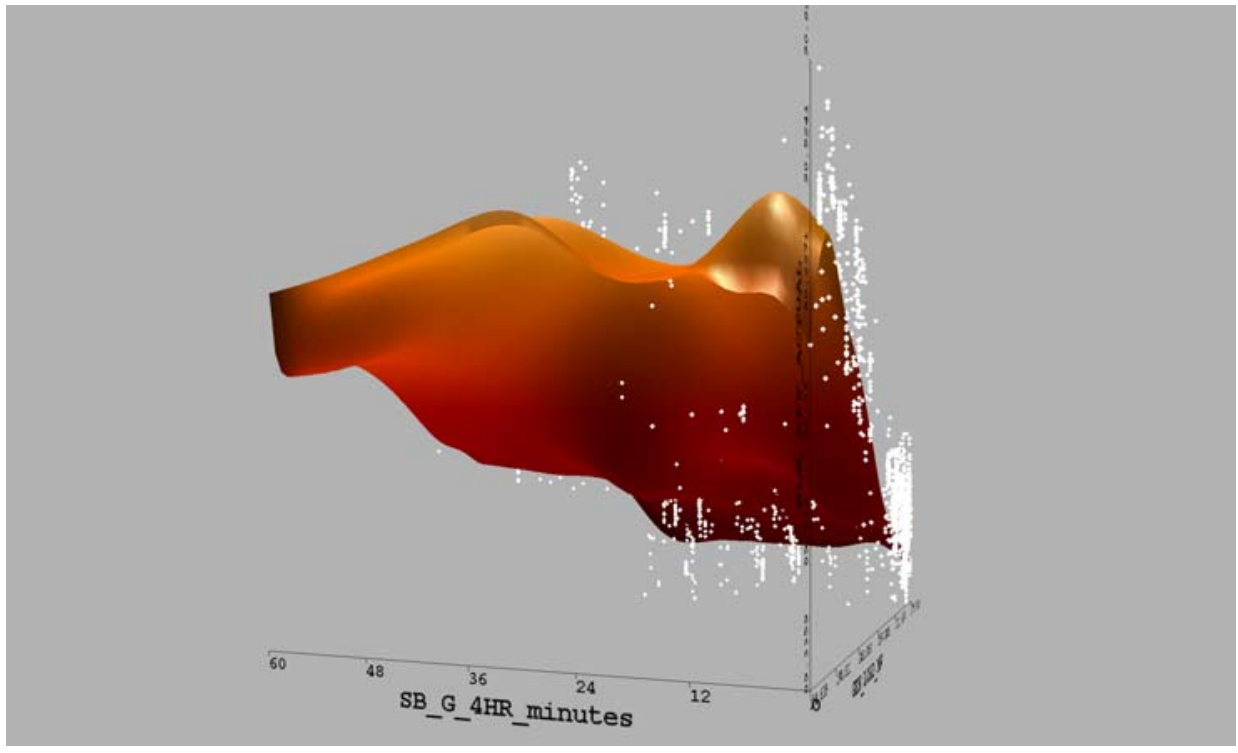

Figure \#23 - Boiler Efficiency vs. Load vs. Sootblower Duty (Group G)

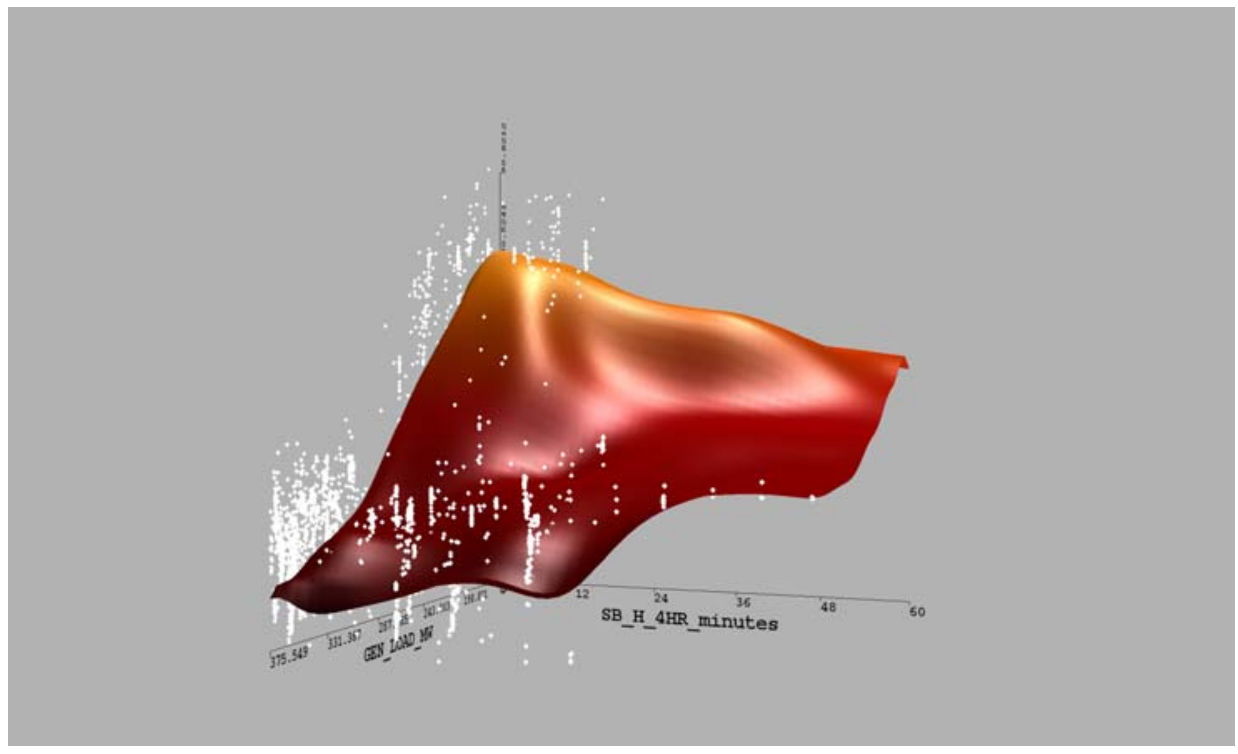

Figure \#24 - Boiler Efficiency vs. Load vs. Sootblower Duty (Group H) 


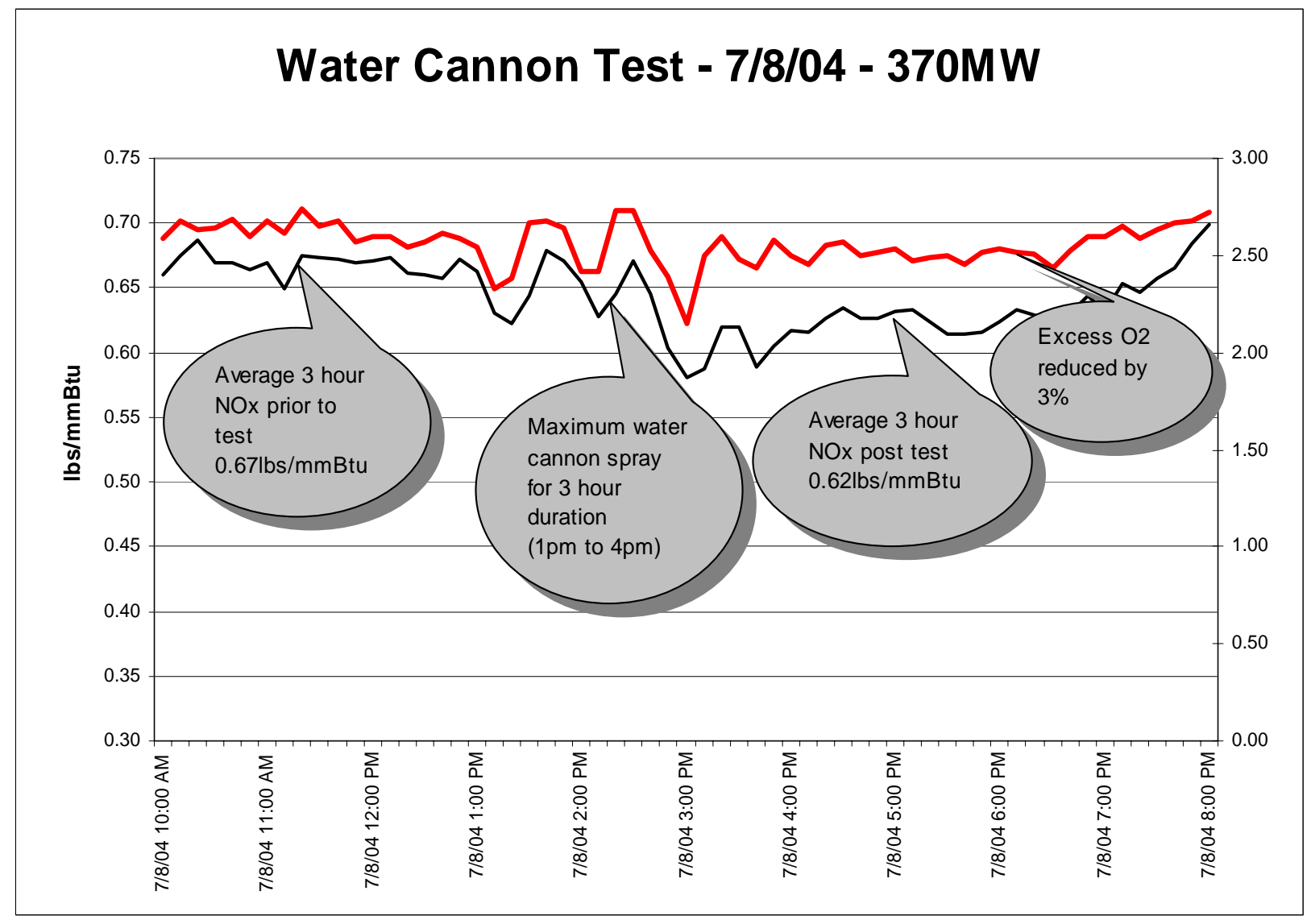

Figure 25 - Water Cannon Test Results

A test of the water cannon system was conducted on July 8, 2004 with the objective of documenting NOx reduction potential of the system. Of the four cannons in the system, two were disabled. These two cannons normally targeted the rear wall of the furnace and comprised a small area as compared to the total surface to be cleaned. Nonetheless, the two remaining active cannons were reprogrammed to clean the rear wall. Accordingly, all water cannon target areas of the furnace were included in the test. Data was collected prior to the test, during the test and after the test. As can be observed in the graph, the NOx emissions prior to the test averaged $0.67 \mathrm{lbs} / \mathrm{mBtu}$ and $0.62 \mathrm{lbs} / \mathrm{mBtu}$ following the test. The NOx emissions during the test fluctuated which may be attributable to water quenching. Excess $\mathrm{O} 2$ measurements also fluctuated during the test, which was coincident with the reduced NOx readings.

Clyde Bergmann was on site prior to the test to ensure that the water cannons were functional and calibrated. The water cannons were last operated approximately twenty-four hours prior to the test while the steam sootblowers were operated normally. The majority of the reduction in NOx emissions following the test can be attributed to reduced levels of excess $\mathrm{O} 2$.

In conclusion the effectiveness of the water cannon system to reduce NOx emissions was found to be negligible in the Big Bend Unit 2 Riley turbo furnace. Based upon this in conjunction with the repeated failures of the system has resulted in the determination to remove the water 
cannon system from further consideration and testing relative to neural network sootblower optimization. Additional data analysis is on-going and will be provided in future reports.

Summary of Preliminary Observations

- In addition to combustion parameters there is strong evidence that sootblowing is impacting NOx.

- The D series and E series sootblowers seem to be the most effective for NOx control whereas the convective sootblowers have the greatest impact toward boiler efficiency.

- There is evidence that optimizing sootblowing duty cycle will improve all around boiler operation and reduce NOx.

- Combustion/sootblowing testing combination is needed to capture best NOx settings.

- Mill levels are a factor in combustion in this boiler and can be related to NOx emissions.

- Water cannons are not effective for NOx control in this Riley turbo wet bottom furnace. 


\section{CONCLUSION:}

The project remains in the operational, developmental and parametric testing stage in preparation of neural network control. Overall the systems supplied are functional, however several smaller items have hindered the programs progress. The respective suppliers have been cooperative in developing and supplying solutions to those problems. Accordingly, the intent of this project objectives remain the implementation of a neural network based intelligent sootblowing system in conjunction with state-of-the-art controls and instrumentation, to optimize the operation of a utility boiler, and systematically control boiler fouling. State-of-theart heat flux and slag sensors, dual plane acoustic pyrometers, directional water cannons, and integration of boiler cleanliness and performance models with a neural network are some of the prominent components of this project. Operation of the sootblowers can be dynamically controlled based on real-time events and changing conditions within the boiler using on-line, adaptive technology. A new generation of cost-effective sensoring equipment has the potential to provide sufficient measurable inputs to a NN-ISB sootblowing process to meet one or more of the objectives, which may include:

NOx Reduction through more stable control of furnace exit temperatures, and more even distribution of temperature across the furnace exit and convection zones.

Particulate Matter Reduction through reduced excess carbon, uniform ESP inlet temperatures, and coordination of sootblowing execution with ESP rapping execution.

Heat Rate Improvement through improved localized temperature consistency and better control of furnace and subsequent heat transfer zone temperatures.

This could be an extremely cost-effective technology, which has the ability to be readily and easily adapted to virtually any pulverized coal-fired boiler. The net impact to the industry will be the demonstration of a commercially viable system that improves overall plant reliability and operations by reducing production cost, while also minimizing emissions.

Based upon the delays realized from the AccuTemp system and Water Cannon system, the benefits demonstration phase has been extended until December 31, 2004. 
APPENDIX

\section{PEGASUS MONTHLY REPORTS}




\section{Tampa Electric, Neural Network Sootblowing Project Update April 30, 2004}

This information is being provided to you pursuant to the reporting requirements of Contract \#BBX-09-02-02109 between Tampa Electric Company (TECO) and Pegasus Technologies, Inc. (Pegasus). If you have any questions on the information please contact:

Neel Parikh $\quad$ (440) 358-7397

Dave Wroblewski (440) 358-7039

Mark Coffin (865) 310-3858

TECO Sootblowing - job \#132

\section{Completed Progress and Activity to date:}

$\checkmark$ P.O. issued, Kickoff meeting for the project held at site.

$\checkmark$ Obtained Sootblowing related Checklist information from customer.

$\checkmark$ Obtained revised I/O list from customer. Review information and seek clarifications. I/O list finalized.

$\checkmark$ Data communications and networking layout and requirements reviewed and agreed upon with customer.

$\checkmark$ Sun system and relevant peripherals acquired, installed and delivered to plant site.

$\checkmark$ Developed and tested datalink to Solvera system.

$\checkmark$ Interfaced with Solvera and Clyde Bergemann to resolve data communications and system setup issues.

$\checkmark$ Reviewed boiler cleanliness information requirements with customer.

$\checkmark$ NeuSIGHT $^{\circledR}$ workstation configured and installed at site.

$\checkmark$ Input datalink communications to WDPF, PI and Solvera systems is functional. Output datalink verified.

$\checkmark$ Technical review, evaluation, analysis, research and software development related to $2^{\text {nd }}$ stage processing and Al techniques. In progress.

$\checkmark$ Literature review and patent search to ensure uniqueness and differentiation of the proposed technology.

$\checkmark \quad$ Finalized a sub-contract with PCS to implement ACM software.

$\checkmark$ ACM software implementation is in progress. I/O list for monitoring approved by TECO.

$\checkmark$ Participated in project meetings at site. Provided relevant information and updates.

$\checkmark$ Prepared and presented a joint paper at the Electric Power 2003 conference and the PowerGen 2003 conference.

$\checkmark$ Parametric testing at site based on unit availability and maintenance activities. In progress. (eg.water cannons, sub groups)

$\checkmark$ Data analysis and visualization. This is an ongoing activity.

$\checkmark$ Develop neural network models and validate relationships. This is an ongoing activity.

$\checkmark$ Initiated closed-loop operation of available combustion parameters.

$\checkmark$ Regularly issued SB status reports for maintenance purposes.

$\checkmark$ Prepared and presented reports outlining project status and key observations.

$\checkmark$ Completed training session with plant operators and engineers on use of the Pegasus optimization system.

$\checkmark$ Obtained selected baseline data in electronic format from TECO.

$\checkmark$ Pegasus identified and reported problems with cleanliness factor calcs generated by EtaPRO. As configured currently the calcs are of limited value to ISB implementation. As of December 1, 2003 General Physics data was not usable and hence as notified to TECO earlier, Pegasus has moved on to using an alternate set of boiler and calculated parameters to support modeling and system operation over the entire load range.

$\checkmark$ Implemented and verified automated parametric test methods to support efficient testing and project execution.

$\checkmark$ Completed on-site training for ACM sensor validation software.

$\checkmark$ Prepared and provided ACM maintenance manual to TECO.

$\checkmark$ Completed parametric testing with two element pairs of sootblowers.

$\checkmark$ Architected and drafted $2^{\text {nd }}$ stage processing code.

This months completed activities:

- Checked-out and tuned pre, post, PdbCALCS logic and trigger conditions for supporting closed-loop operation with 2 element pairs of sootblowers. 
- Conducted first evaluation (verification and validation) of $2^{\text {nd }}$ stage processing software using realtime plant operating data.

- Made software updates based on preliminary evaluation.

- Conducted preliminary closed-loop testing using recommendations from optimizer and $2^{\text {nd }}$ stage processing.

- Run-time experience in closed-loop mode revealed the need to update Solvera software configuration. Accordingly, relevant activities were coordinated with TECO and Solvera.

- Presented current project implementation status to TECO.

Requested Upcoming Assistance, detail of any Obstacles:

- Pegasus requests assistance for unit availability for parametric and advisory/closed-loop testing during May and June. Pegasus will furnish necessary test plans at the appropriate time.

- Pegasus shall plan to perform the water cannon related scope of work after receiving an authorization to proceed from TECO.

- Per Neel Parikh's email dated Mar 31, 2004 to Solvera and TECO (Mark Rhode), Pegasus is queued for Solvera to complete and verify configuration changes to the Solvera SBC system to support robust closed-loop operation.

- Unit availability to support rating damper related parametric testing.

\section{Planned activities for next month:}

- Monitor runtime (for verification and validation) with $2^{\text {nd }}$ stage processing software using real-time plant operating data. Implement refinements as necessary.

- Undertake additional parametric testing for rating dampers per email request to TECO dated April 2, 2004. This task is awaiting unit availability for supporting relevant test runs.

- Once the rating damper tests are completed, update the combustion model to reflect test data.

- Support activities related to Solvera software configuration changes.

- Implement configuration updates to provide additional data to Solvera system.

- Complete outstanding punch list items to fully accomplish ACM implementation.

- Continue review and documentation of ISB processing techniques. 


\section{Tampa Electric, Neural Network Sootblowing Project Update May 31, 2004}

This information is being provided to you pursuant to the reporting requirements of Contract \#BBX-09-02-02109 between Tampa Electric Company (TECO) and Pegasus Technologies, Inc. (Pegasus). If you have any questions on the information please contact:

Neel Parikh $\quad$ (440) 358-7397

Dave Wroblewski (440) 358-7039

Mark Coffin (865) 310-3858

TECO Sootblowing - job \#132

\section{Completed Progress and Activity to date:}

$\checkmark$ P.O. issued, Kickoff meeting for the project held at site.

$\checkmark$ Obtained Sootblowing related Checklist information from customer.

$\checkmark$ Obtained revised I/O list from customer. Review information and seek clarifications. I/O list finalized.

$\checkmark$ Data communications and networking layout and requirements reviewed and agreed upon with customer.

$\checkmark$ Sun system and relevant peripherals acquired, installed and delivered to plant site.

$\checkmark$ Developed and tested datalink to Solvera system.

$\checkmark$ Interfaced with Solvera and Clyde Bergemann to resolve data communications and system setup issues.

$\checkmark$ Reviewed boiler cleanliness information requirements with customer.

$\checkmark$ NeuSIGHT $^{\circledR}$ workstation configured and installed at site.

$\checkmark$ Input datalink communications to WDPF, PI and Solvera systems is functional. Output datalink verified.

$\checkmark$ Technical review, evaluation, analysis, research and software development related to $2^{\text {nd }}$ stage processing and Al techniques. In progress.

$\checkmark$ Literature review and patent search to ensure uniqueness and differentiation of the proposed technology.

$\checkmark \quad$ Finalized a sub-contract with PCS to implement ACM software.

$\checkmark$ ACM software implementation is in progress. I/O list for monitoring approved by TECO.

$\checkmark$ Participated in project meetings at site. Provided relevant information and updates.

$\checkmark$ Prepared and presented a joint paper at the Electric Power 2003 conference and the PowerGen 2003 conference.

$\checkmark$ Parametric testing at site based on unit availability and maintenance activities. In progress. (eg.water cannons, sub groups)

$\checkmark$ Data analysis and visualization. This is an ongoing activity.

$\checkmark$ Develop neural network models and validate relationships. This is an ongoing activity.

$\checkmark$ Initiated closed-loop operation of available combustion parameters.

$\checkmark$ Regularly issued SB status reports for maintenance purposes.

$\checkmark$ Prepared and presented reports outlining project status and key observations.

$\checkmark$ Completed training session with plant operators and engineers on use of the Pegasus optimization system.

$\checkmark$ Obtained selected baseline data in electronic format from TECO.

$\checkmark$ Pegasus identified and reported problems with cleanliness factor calcs generated by EtaPRO. As configured currently the calcs are of limited value to ISB implementation. As of December 1, 2003 General Physics data was not usable and hence as notified to TECO earlier, Pegasus has moved on to using an alternate set of boiler and calculated parameters to support modeling and system operation over the entire load range.

$\checkmark$ Implemented and verified automated parametric test methods to support efficient testing and project execution.

$\checkmark$ Completed on-site training for ACM sensor validation software.

$\checkmark$ Prepared and provided ACM maintenance manual to TECO.

$\checkmark$ Completed parametric testing with two element pairs of sootblowers.

$\checkmark$ Architected and drafted $2^{\text {nd }}$ stage processing code.

This months completed activities:

- Provided necessary support related to Solvera software configuration updates. Relevant activities were coordinated with TECO and Solvera. 
- Coordinated with TECO and Clyde Bergemann regarding water cannon test procedures.

- Monitored Pegasus system operation and data interfaces.

- NOTE: Pegasus was ON HOLD for most of May 2004, awaiting sootblower control system and Unit availability for further testing.

\section{Requested Upcoming Assistance, detail of any Obstacles:}

- Pegasus requests assistance for unit availability for parametric and advisory/closed-loop testing during June and July. Pegasus will furnish necessary test plans at the appropriate time.

- Pegasus shall plan to perform the water cannon related scope of work after receiving an authorization to proceed from TECO.

- Unit availability to support rating damper related parametric testing.

\section{Planned activities for next month:}

- Monitor runtime (for verification and validation) with $2^{\text {nd }}$ stage processing software using real-time plant operating data. Implement refinements as necessary.

- Undertake additional parametric testing for rating dampers per email request to TECO dated April 2, 2004. This task is awaiting unit availability for supporting relevant test runs.

- Once the rating damper tests are completed, update the combustion model to reflect test data.

- Implement configuration updates to provide additional data to Solvera system.

- Complete outstanding punch list items to fully accomplish ACM implementation.

- Continue review and documentation of ISB processing techniques.

- Presuming Unit and control systems availability, Pegasus targets to accomplish majority of the outstanding tasks in June and July. 


\section{Tampa Electric, Neural Network Sootblowing Project Update June 30, 2004}

This information is being provided to you pursuant to the reporting requirements of Contract \#BBX-09-02-02109 between Tampa Electric Company (TECO) and Pegasus Technologies, Inc. (Pegasus). If you have any questions on the information please contact:

Neel Parikh $\quad$ (440) 358-7397

Dave Wroblewski (440) 358-7039

Mark Coffin (865) 310-3858

TECO Sootblowing - job \#132

\section{Completed Progress and Activity to date:}

$\checkmark$ P.O. issued, Kickoff meeting for the project held at site.

$\checkmark$ Obtained Sootblowing related Checklist information from customer.

$\checkmark$ Obtained revised I/O list from customer. Review information and seek clarifications. I/O list finalized.

$\checkmark$ Data communications and networking layout and requirements reviewed and agreed upon with customer.

$\checkmark$ Sun system and relevant peripherals acquired, installed and delivered to plant site.

$\checkmark$ Developed and tested datalink to Solvera system.

$\checkmark$ Interfaced with Solvera and Clyde Bergemann to resolve data communications and system setup issues.

$\checkmark$ Reviewed boiler cleanliness information requirements with customer.

$\checkmark$ NeuSIGHT $^{\circledR}$ workstation configured and installed at site.

$\checkmark$ Input datalink communications to WDPF, PI and Solvera systems is functional. Output datalink verified.

$\checkmark$ Technical review, evaluation, analysis, research and software development related to $2^{\text {nd }}$ stage processing and Al techniques. In progress.

$\checkmark$ Literature review and patent search to ensure uniqueness and differentiation of the proposed technology.

$\checkmark \quad$ Finalized a sub-contract with PCS to implement ACM software.

$\checkmark$ ACM software implementation is in progress. I/O list for monitoring approved by TECO.

$\checkmark$ Participated in project meetings at site. Provided relevant information and updates.

$\checkmark$ Prepared and presented a joint paper at the Electric Power 2003 conference and the PowerGen 2003 conference.

$\checkmark$ Parametric testing at site based on unit availability and maintenance activities. In progress. (eg.water cannons, sub groups)

$\checkmark$ Data analysis and visualization. This is an ongoing activity.

$\checkmark$ Develop neural network models and validate relationships. This is an ongoing activity.

$\checkmark$ Initiated closed-loop operation of available combustion parameters.

$\checkmark$ Regularly issued SB status reports for maintenance purposes.

$\checkmark$ Prepared and presented reports outlining project status and key observations.

$\checkmark$ Completed training session with plant operators and engineers on use of the Pegasus optimization system.

$\checkmark$ Obtained selected baseline data in electronic format from TECO.

$\checkmark$ Pegasus identified and reported problems with cleanliness factor calcs generated by EtaPRO. As configured currently the calcs are of limited value to ISB implementation. As of December 1, 2003 General Physics data was not usable and hence as notified to TECO earlier, Pegasus has moved on to using an alternate set of boiler and calculated parameters to support modeling and system operation over the entire load range.

$\checkmark$ Implemented and verified automated parametric test methods to support efficient testing and project execution.

$\checkmark$ Completed on-site training for ACM sensor validation software.

$\checkmark$ Prepared and provided ACM maintenance manual to TECO.

$\checkmark$ Completed parametric testing with two element pairs of sootblowers.

$\checkmark$ Architected and drafted $2^{\text {nd }}$ stage processing code. 


\section{This months completed activities:}

- Updated Pegasus system to write timeout value to Solvera system. This helps monitor health of the relevant datalink and prevents inadvertent switch over to Pegasus/Manual mode of sootblower control.

- Tuned Pegasus system to operate under different unit conditions.

- Generated, reviewed and obtained approval for test plan and coordinated scheduling of rating dampers testing.

- Monitored runtime (for verification and validation) with $2^{\text {nd }}$ stage processing software using real-time plant operating data. Reviewed data and implemented refinements as necessary.

- Monitored Pegasus system operation and data interfaces.

- NOTE: Pegasus was ON HOLD for part of Jun 2004, awaiting Unit availability for further testing.

- Supported joint paper presentation activities related to EPRI ISB Workshop.

\section{Requested Upcoming Assistance, detail of any Obstacles:}

- Pegasus requests assistance for unit availability for parametric and advisory/closed-loop testing during July.

- Pegasus shall plan to perform the water cannon related scope of work after receiving an authorization to proceed from TECO.

- Unit availability to support rating damper related parametric testing.

\section{Planned activities for next month:}

- Continue monitoring runtime (for verification and validation) with $2^{\text {nd }}$ stage processing software using real-time plant operating data. Implement tuning/refinements as determined necessary.

- Undertake additional parametric testing for rating dampers per email request to TECO dated April 2, 2004. This task is scheduled for the week of July 6, 2004, presuming unit availability for supporting relevant test runs.

- Once the rating damper tests are completed, update the combustion model to reflect test data.

- Implement configuration updates to provide additional data to WDPF system.

- Complete outstanding punch list items to fully accomplish ACM implementation.

- Continue review and documentation of ISB processing techniques.

- On site testing of Solvera-Pegasus datalink timeout feature.

- Support water cannon testing and data evaluation per TECO's request.

- Validate/verify availability of and data from Acoustic Pyrometer system. 